Research Article

\title{
Three-Dimensional Numerical Calculation Model for Static Behavior Simulation of Cross-Laminated Timber Plates under Thermal Environment
}

\author{
Wenliang Hu (D), ${ }^{1}$ Wei Hou, ${ }^{1}$ Zhao Zhu ${ }^{D},{ }^{1}$ and Xuhui Huang ${ }^{2}$ \\ ${ }^{1}$ School of Highway, Chang'an University, Xi'an 710064, China \\ ${ }^{2}$ School of Civil Engineering, Anhui Jianzhu University, Anhui 230601, China \\ Correspondence should be addressed to Wenliang Hu; 2015021022@chd.edu.cn
}

Received 1 August 2020; Revised 1 October 2020; Accepted 26 December 2020; Published 12 January 2021

Academic Editor: Yuqiang Xu

Copyright (c) 2021 Wenliang $\mathrm{Hu}$ et al. This is an open access article distributed under the Creative Commons Attribution License, which permits unrestricted use, distribution, and reproduction in any medium, provided the original work is properly cited.

\begin{abstract}
Cross-laminated timber (CLT) is well known as an interesting technical and economical product for modern wood structures. The use of CLT for modern construction industry has become increasingly popular in particular for residential timber buildings. Analyzing the CLT behavior in high thermal environment has attracted scholars' attention. Thermal environment greatly influences the CLT properties and load bearing capacity of CLT, and the investigation can form the basis for predicting the structural response of such CLT-based structures. In the present work, the finite element method (FEM) is employed to analyze the thermal influence on the deformation of CLT. Furthermore, several factors were taken into consideration, including board layer number, hole conformation, and hole position, respectively. In order to determine the influence, several numerical models for different calculation were established. The calculation process was validated by comparing with published data. The performance is quantified by demonstrating the temperature distribution and structural deformation.
\end{abstract}

\section{Introduction}

Wood possesses excellent mechanical and physical properties which is well known as an environmentally sustainable building material with a pleasant appearance and, thus, is particularly suitable for residential buildings, public buildings, and industrial buildings $[1,2]$. In recent years, timber is undergoing a revival and recapturing market shares from other building materials, and its world market was witnessed a considerable growth in the total production $[3,4]$.

The revival of timber is largely beneficial from the development of the innovative laminar timber product crosslaminated timber (CLT). This timber product commonly composed of an uncertain number of layers, each made of boards placed side-by-side, which were arranged crosswise to each other at an angle of $90^{\circ}$ [5]. Comparing with the traditional wood, CLT possesses a higher structural capacity, which makes it suitable for walls, floor slabs, and roofs, and is also a wood material which is suitable for large-scale and high-rise building constructions [6]. CLT can be constructed into large solid timber panels, and this allows the transfer of high vertical loads and guarantees a high building stiffness and robustness. Another advantage of CLT is an excellent thermal insulation. There is a majority of researches investigating the fire behavior of CLT panels. Eurocode gives a simplified method for the calculation of the mechanical resistance of timber beams and columns (reduced crosssectional model) [7]. Fragiacomo et al. studied the fire resistance of CLT panels located out of the plane [8]. Klippel et al. investigated the fire safety of CLT, and the fire design has been done $[9,10]$. Schmid et al. has modeled and tested the fire-exposed CLT, and they also proposed results from fire tests of beam strips cut from CLT with adequate side protection in bending in order to achieve 1D heat transfer [11-13]. Frangi et al. presented the experimental and numerical analyses of the fire behavior of CLT panels, and they 
further compared the fire behavior of CLT panels with homogeneous timber panels [14, 15]. Experiment was performed, and 3D finite element model was developed to predict the fire behavior of loaded CLT panels [16]. The performance of CLT and hybrid structure was presented $[17,18]$. From numerous literature surveys, we can see that the experimental test was expensive and random.

As the fire tests of CLT are crucial to ensure the safety standards in the timber buildings, the investigation on the CLT behavior in high thermal environment has drawn our attention. The experimental fire tests were costly, and it is of great importance to develop numerical models that can be used to extend the few experimental results available to different configurations and different load conditions. Researchers also presented the homogenization method to build the CLT parameters, and results were compared with the experiments to reveal the potential predictive capabilities of the multiscale modeling for the analysis of wood material $[3,19]$. Researchers made efforts to propose numerical models, and they were implemented in existing software [20-22]. The finite element method (FEM) was commonly utilized to study the architectural engineering issues [23-25].Takeda and Mehaffey have proposed a 2D computer model for predicting heat transfer through uninsulated wood-stud walls [26]. Franssen et al. employed finite element method to test the heat transfer of 3D beam [27]. A high-order FEM for vibration analysis of CLT structures and the suitable ranges for the stiffness parameters of the finite elements which represent the junctions were identified [28]. Michele Betti et al. proposed a new test method to assess the quality of face bonding in CLT [29]. The present literatures were focused on analysis of the structural influence on the CLT performance. And the literatures reveal that the FEM was the most widely used method. As a result, we choose to use FEM to analyze the behavior of the structure with change in temperature.

As is known from all other timber products with crosswise layering, CLT possesses a high dimensional stability in-plane. But, along thickness direction, swelling and shrinking have to be considered equal to solid timber. This work presented in this paper is concerned with numerical simulations of CLT plates. We made the first attempt to fill the gap in illustrating the static behavior of CLT plates subject to thermal loads. The finite element method was employed, and the influence of board layer number, hole dimension, hole conformation, and hole position on the CLT structural performance was taken into account. The influence was quantified by demonstrating the temperature distribution and structural deformation of CLT structure. Several numerical examples were established to investigate these influences.

\section{Finite Element Method}

The geometric equations of a CLT structure are basically listed below:

$$
\begin{aligned}
\varepsilon_{x} & =-E_{x}^{-1}\left(\sigma_{x}-\mu_{x z} \sigma_{z}-\mu_{x y} \sigma_{y}\right), \\
\varepsilon_{y} & =-E_{x}^{-1}\left(-\mu_{y x} \sigma_{x}-\mu_{y z} \sigma_{z}+\sigma_{y}\right), \\
\varepsilon_{z} & =-E_{z}^{-1}\left(-\mu_{z x} \sigma_{x}+\sigma_{z}-\mu_{z y} \sigma_{y}\right), \\
\gamma_{y z} & =-\frac{\tau_{y z}}{G_{y z}} \\
\gamma_{z x} & =-\frac{\tau_{z x}}{G_{z x}} \\
\gamma_{x y} & =-\frac{\tau_{x y}}{G_{x y}}
\end{aligned}
$$

where $\varepsilon_{x}, \varepsilon_{y}$, and $\varepsilon_{z}$ represent the strain components in the $x$, $y$, and $z$ directions; $E_{x}, E_{y}$, and $E_{z}$ represent the elastic modulus in the $x, y$, and $z$ directions; $\sigma_{x}, \sigma_{y}$, and $\sigma_{z}$ represent the stress components in the $x, y$, and $z$ directions; $\mu_{x z}, \mu_{\mathrm{y} z}$, and $\mu_{x y}$ represent Poisson's ratio and are expressed as $\mu_{x z}=\varepsilon_{z} / \varepsilon_{x}, \mu_{y z}=\varepsilon_{z} / \varepsilon_{y}$, and $\mu_{x y}=\varepsilon_{y} / \varepsilon_{x} ; \gamma_{y z}, \tau_{z x}$, and $G_{y x}$ represent the shear strain, shear stress, and shear modulus, respectively.

The heat transfer for the CLT plate is assembled by the partial differential equation:

$$
-D \nabla T=Q
$$

where $T$ represents the temperature, $D$ represents the thermal conductivity parameter matrix, and $Q$ is heat flux matrix:

$$
\begin{aligned}
\nabla T & =\left\{\begin{array}{l}
\frac{\partial T}{\partial x} \\
\frac{\partial T}{\partial y} \\
\frac{\partial T}{\partial z}
\end{array}\right\}, \\
D & =\left[\begin{array}{ccc}
k_{x x}(T) & 0 & 0 \\
0 & k_{y y}(T) & 0 \\
0 & 0 & k_{z z}(T)
\end{array}\right],
\end{aligned}
$$

where $k_{x x}(T), k_{y y}(T)$, and $k_{z z}(T)$ represent the thermal conductivities in the $x, y$, and $z$ directions.

The thermal expansion coefficient of wood parallel was ranging from about 3.1 to $4.5 \times 10^{-6} \mathrm{~K}^{-1}$. And the radial thermal expansion $\alpha_{y}$ and tangential thermal expansion $\alpha_{z}$ are the coefficients approximated by the following equations, where $G_{0}$ is the specific gravity:

$$
\begin{aligned}
& \alpha_{y}=\left(32.4 G_{0}+9.9\right) \times 10^{-6} K^{-1}, \\
& \alpha_{z}=\left(32.4 G_{0}+18.4\right) \times 10^{-6} K^{-1} .
\end{aligned}
$$




\section{The FEM for Analyzing CLT under High- Temperature Environment}

Themotion equations for the thermal structural coupling analysis can be written as

$$
\begin{aligned}
{\left[\begin{array}{cc}
\mathbf{K}_{\mathrm{uu}} & \mathbf{K}_{\mathrm{ut}} \\
0 & \mathbf{K}_{\mathrm{tt}}
\end{array}\right]\left[\begin{array}{l}
\mathbf{u} \\
\mathbf{T}
\end{array}\right] } & =\left[\begin{array}{c}
\mathbf{F} \\
\mathbf{Q}
\end{array}\right], \\
\mathbf{K}_{\mathrm{uu}} & =\int_{\Omega} \bar{B}_{\mathrm{u}}^{i \mathrm{~T}}[\mathbf{C}] \bar{B}_{\mathrm{t}}^{i} \mathrm{~d} \Omega, \\
\mathbf{K}_{\mathrm{ut}} & =\int_{\Omega} \bar{B}_{\mathrm{u}}^{i \mathrm{~T}}[\mathbf{C}][\alpha] \bar{B}_{\mathrm{t}}^{i} \mathrm{~d} \Omega, \\
\mathbf{K}_{\mathrm{tt}} & =\int_{\Omega} \bar{B}_{\mathrm{t}}^{i \mathrm{~T}}[\boldsymbol{\varepsilon}] \bar{B}_{\mathrm{t}}^{i} \mathrm{~d} \Omega, \\
\mathbf{F} & =\int_{S} \mathbf{N}^{\mathrm{T}} F \mathrm{~d} S, \\
\mathbf{Q} & =\int_{S} \mathbf{N}^{\mathrm{T}} \mathrm{Q} \mathrm{d} S,
\end{aligned}
$$

where $\mathbf{K}$, $\mathbf{u}$, and $\mathbf{T}$ represent the stiffness, displacement, and temperature matrix; $\mathbf{F}$ and $\mathbf{Q}$ represent the mechanical and thermal load matrix; C, $\boldsymbol{\varepsilon}$, and $\alpha$ denote the elastic, conductivity, and thermal expansion coefficients matrix.

The FEM in calculating the CLT in thermal environment was verified with a comparison with research [30]. A five layer CLT plate was analyzed, and the thickness direction temperature distribution at point $A(x=218.75, y=737.5)$ was plotted (Figure 1).

The FEM result matched well with the reference result. The relative error is around 5\%, and the maximum relative error does not exceed $15 \%$.

\section{Numerical Examples}

In this section, we established several numerical examples to investigate the static characteristics of CLT. The numerical examples are all on the basic of a rectangle plate, the basic configuration of the CLT plate is shown in Figure 2. The radiata pine was applied for analysis, and the parameters are listed in Table 1. The thermal boundary condition is given in Figure 2, the ambient temperature is $0^{\circ} \mathrm{C}$, and the corner of the plate was fixed $\left(u_{x}=u_{y}=u_{z}=0\right.$, at points $A, B, D$, and $\left.H\right)$. We take into account of the impact of several factors on the performance of the CLT. The board layer number influence, hole conformation influences, and hole position influence were analyzed by demonstrating the temperature distribution in layer at depth positions $h=40 \mathrm{~mm}, 80 \mathrm{~mm}, 120 \mathrm{~mm}$, and $160 \mathrm{~mm}$, and the contour plots of plate deformation in $x$, $y$, and $z$ coordinate directions. Furthermore, the $x$-, $y$-, and $z$ direction displacements were also given along the plate borderlines $A B$ and $B D$, also along the thickness directions $B C, F G$, and $D E$.

4.1. CLT Board Layer Influence. The correctness of the FEM in calculating the CLT deformation under high-temperature environment was validated previously. Then, we illustrated the board layer effects on the CLT behavior, three kinds of
CLT were analyzed, and they were composed of 3 board layers, 5 board layers, and 7 board layers (Figure 3). In Figure 4 , the temperature distribution of layers at depth position $h=40 \mathrm{~mm}, 80 \mathrm{~mm}, 120 \mathrm{~mm}$, and $160 \mathrm{~mm}$ was demonstrated. In Figure 5, the contour plots of plate deformation in $x, y$, and $z$ coordinate directions are given. The displacement along the CLT plate borderlines ( $A B$ line $u_{x}$, $B D$ line $u_{y}$, and $B D$ line $u_{z}$ ) and the displacement along the thickness direction ( $B C$ line $u_{x}, D E$ line $u_{y}, F G$ line $u_{z}$ ) are demonstrated in Figures 6 and 7.

From Figure 4, we can see that 5 board layers have a different temperature distribution form from the other two CLT plates. From Figures 5-7, effect of the board layer on the CLT behavior is shown. For $u_{x}$ displacement component, the result increases with the increase in board layer. For $u_{y}$ and $u_{z}$ displacement components, the result decreases with the increase in board layer increase. Furthermore, the displacement distributions along plate borderlines and thickness reveal that the board layer plays a strong effect on $u_{z}$ displacement components than the other two. Hence, the $u_{z}$ displacement component was more sensitive to the thermal load, and then the load bearing capacity of CLT plates will be influenced.

4.2. Hole Conformation Influence. A square hole was framed in the centre of the 5-board layer rectangular plate. When investigating the hole conformation influence on the CLT static behavior, particular attention should be paid to ensure that the results of the different models remain comparable. And the conformation and dimension coupling influence were further investigated. Five kinds of square hole length dimensions were developed $l=d=177.2 \mathrm{~mm}$, $l=d=354.4 \mathrm{~mm}, l=d=531.6 \mathrm{~mm}, l=502.4 \mathrm{~mm} d=250 \mathrm{~mm}$, and $l=420 \mathrm{~mm} d=300 \mathrm{~mm}$ (Figure 8). The temperature distribution and the contour plots of plate deformation were given (Figures 9-14).

Figures 9 and 11 demonstrate the temperature distribution in different configurations, from which we can get the same conclusion that the temperature regularly changes along radial direction. In Figures 10 and 12, the square hole dimension effects on the CLT deformation are shown, and it brings a slight effect on the deformation of the plate. In Figures 13 and 14 , we can see that the $u_{z}$ displacement component is the most sensitive to the hole radius variation.

4.3. Hole Position Influence. The hole position also has an influence on the CLT structural performance. When investigating the holes' position influence on the CLT behavior, we constructed four CLT plate models. The concrete structural forms and dimensions are shown in Figure 15. Figures 16-19 demonstrate the temperature distribution and the contour plots of plate deformation.

Figure 16 demonstrate the temperature distribution in models, from which we can see the difference among these models. In Figures 17-19, the hole position effects on the CLT deformation are shown. The hole position brings a strong effect on the deformation of the plate, and the effect was obviously shown in the displacement distribution. 


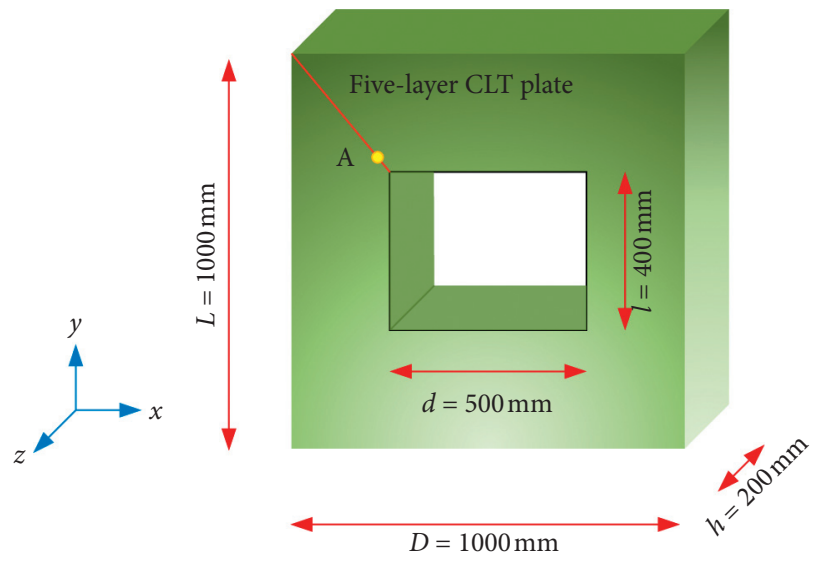

(a)

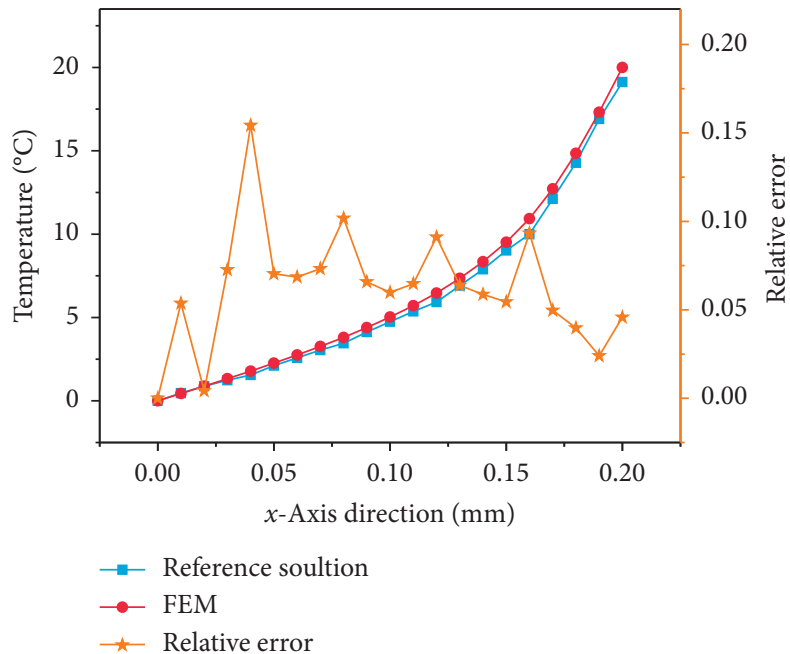

(b)

Figure 1: (a) Schematic diagram of the CLT plate in [30]. (b) Temperature distribution at point A and the relative error of the FEM.
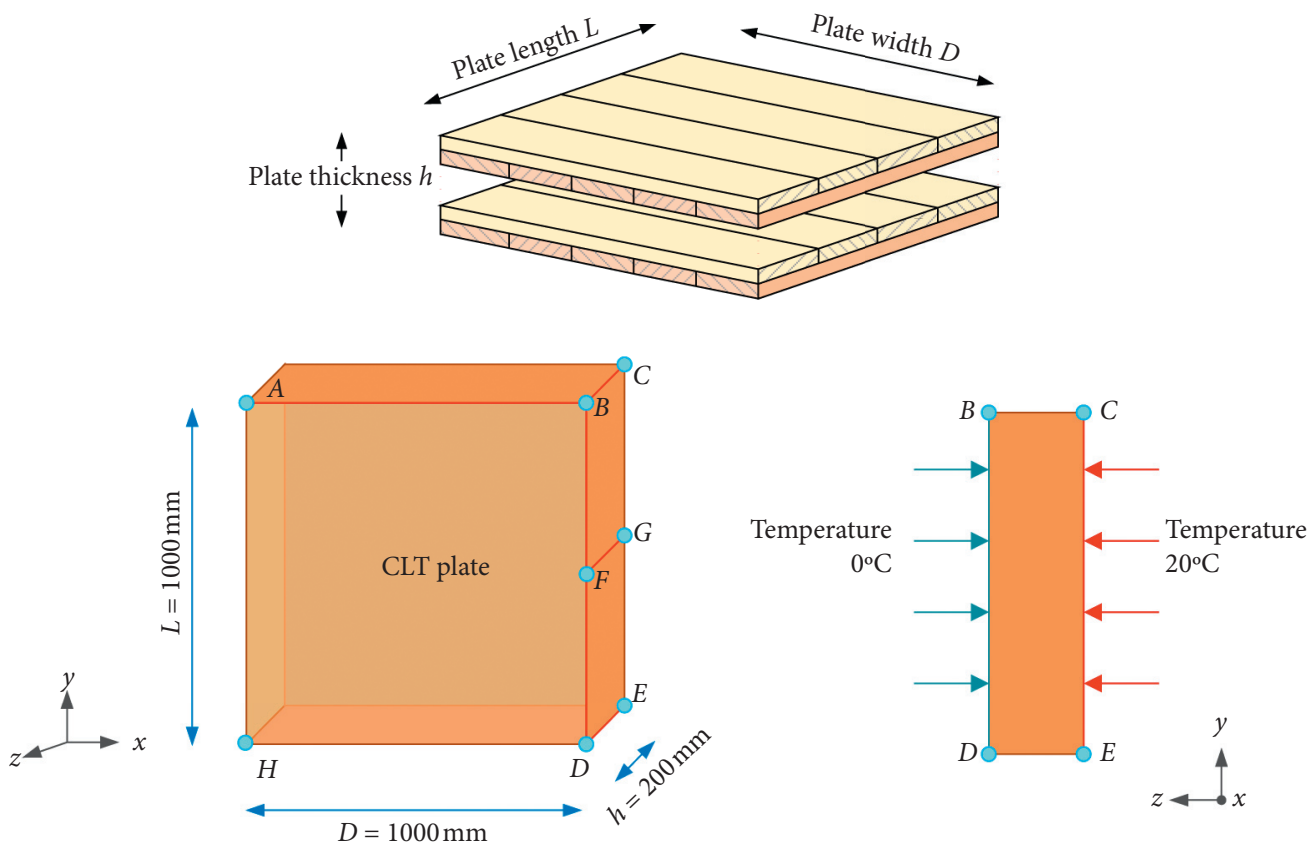

FIgURE 2: Schematic diagram of a CLT plate.

TABLE 1: Material parameters of radiata pine.

\begin{tabular}{|c|c|c|c|c|c|c|c|c|}
\hline Material & Density $\left(\mathrm{g} / \mathrm{cm}^{3}\right)$ & Moisture content (\%) & $E_{x}(\mathrm{MPa})$ & $E_{z}(\mathrm{MPa})$ & $E_{y}(\mathrm{MPa})$ & $G_{x y}(\mathrm{MPa})$ & $G_{x z}(\mathrm{MPa})$ & $G_{y z}(\mathrm{MPa})$ \\
\hline Radiata pine & $\begin{array}{c}0.550 \\
a_{x}\left(\mathrm{~K}^{-1}\right) \\
4 \times 10^{-6}\end{array}$ & $\begin{array}{cc}a_{y}\left(\mathrm{~K}^{-1}\right) & a_{z}\left(\mathrm{~K}^{-1}\right) \\
27.7 \times 10^{-6} & 36.2 \times 10^{-6}\end{array}$ & $\begin{array}{c}16272 \\
k_{x x}(\mathrm{~W} / \mathrm{mK}) \\
0.35\end{array}$ & $\begin{array}{c}1103 \\
k_{y y}(\mathrm{~W} / \mathrm{mK}) \\
0.16\end{array}$ & $\begin{array}{c}573 \\
k_{z z}(\mathrm{~W} / \mathrm{mK}) \\
0.16\end{array}$ & $\begin{array}{l}1172 \\
\mathrm{M}_{x y} \\
0.42\end{array}$ & $\begin{array}{l}676 \\
\mathrm{M}_{x z} \\
0.51\end{array}$ & $\begin{array}{c}66 \\
\mathrm{M}_{y z} \\
0.68\end{array}$ \\
\hline
\end{tabular}




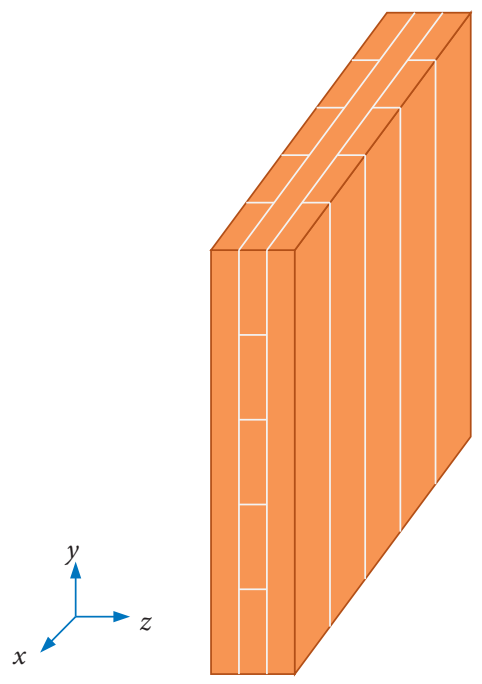

(a)

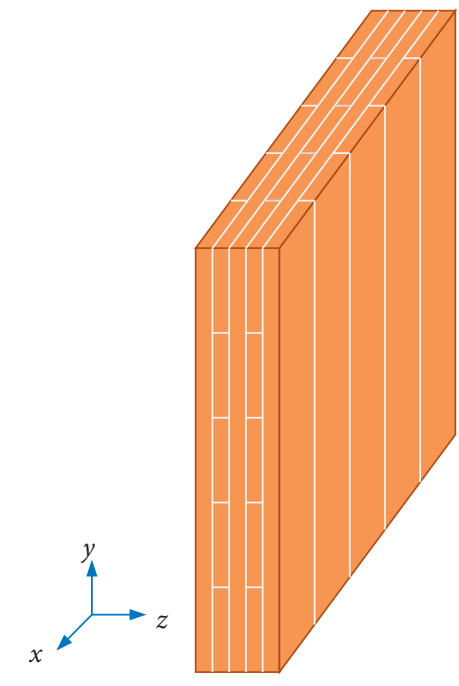

(b)

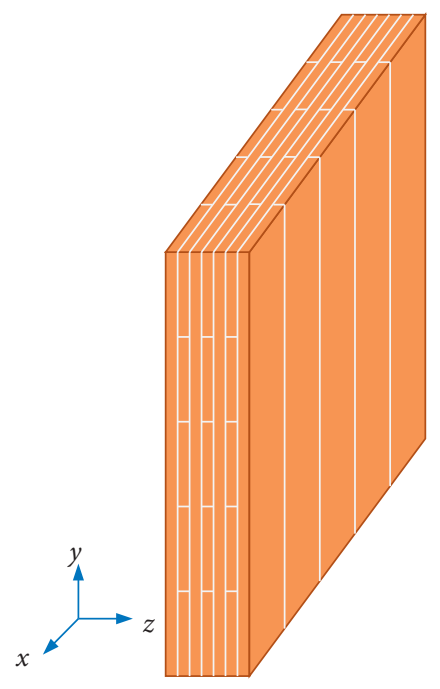

(c)

FIgURE 3: The CLT plate with three different board layers. (a) 3-layer CLT plate. (b) 5-layer CLT plate. (c) 7-layer CLT plate.
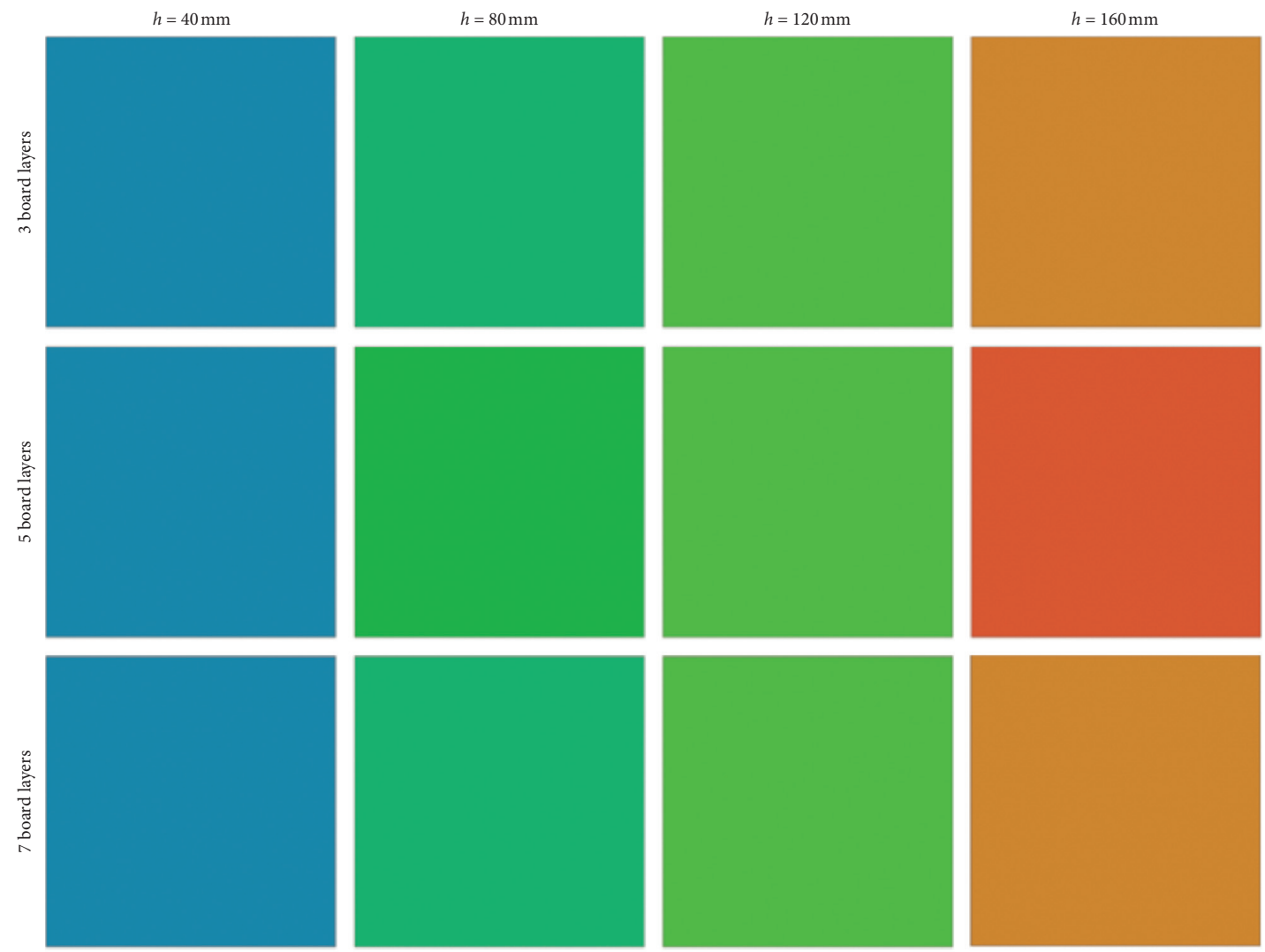

$-2.731 e+02-2.715 e+02-2.699 e+02-2.683 e+02-2.666 e+02-2.650 e+02-2.634 e+02-2.618 e+02-2.601 e+02-2.585 e+02-2.569 e+02-2.553 e+02-2.537 e+02$

FIGURE 4: The temperature distribution of the CLT plate with various layer components at depth positions $h=40 \mathrm{~mm}, 80 \mathrm{~mm}, 120 \mathrm{~mm}$, and $160 \mathrm{~mm}$. 

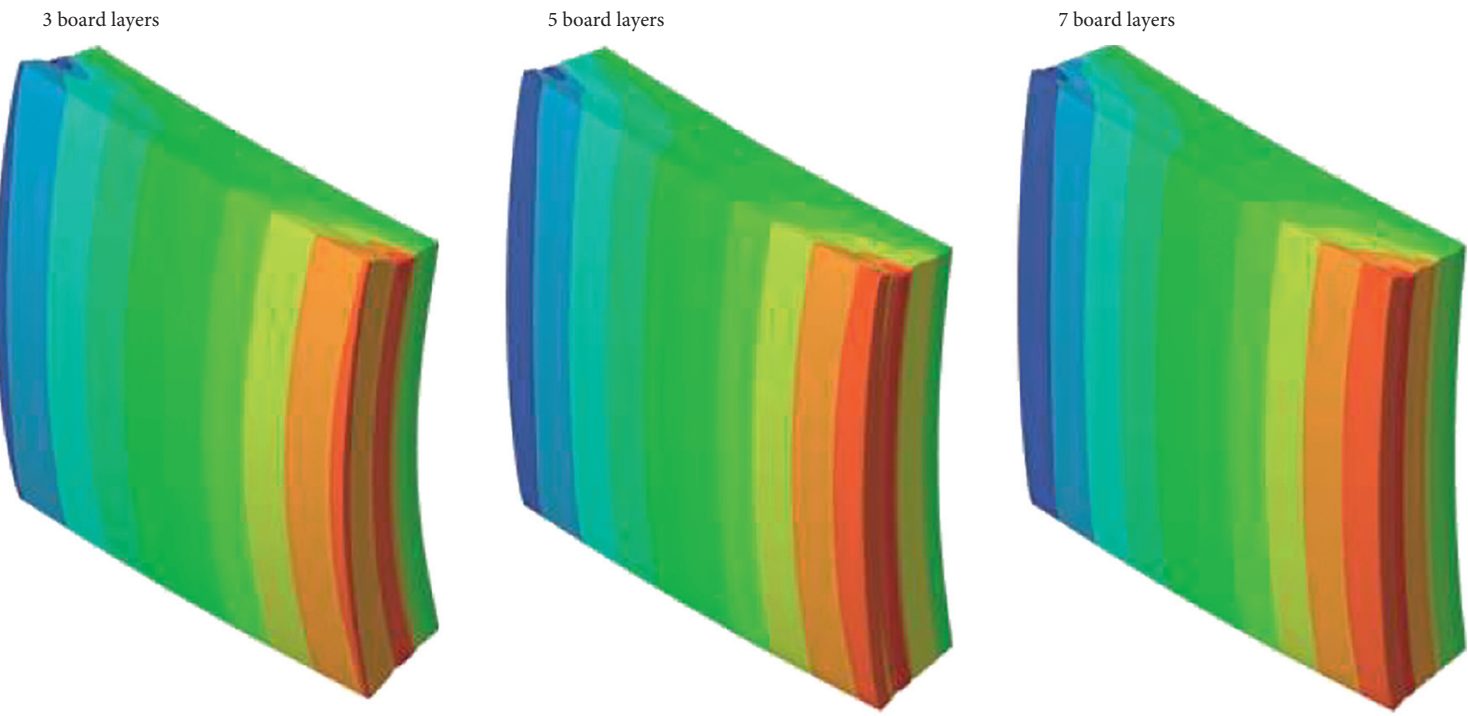

$u_{x}$

$-6.343 e-02-5.286 e-02-4.229 e-02 \quad-3.172 e-02 \quad-2.114 e-02-1.057 e-02 \quad+5.588 e-09+1.057 e-02+2.114 e-02 \quad+3.172 e-02+4.229 e-02+5.286 e-02+6.343 e-02$

(a)

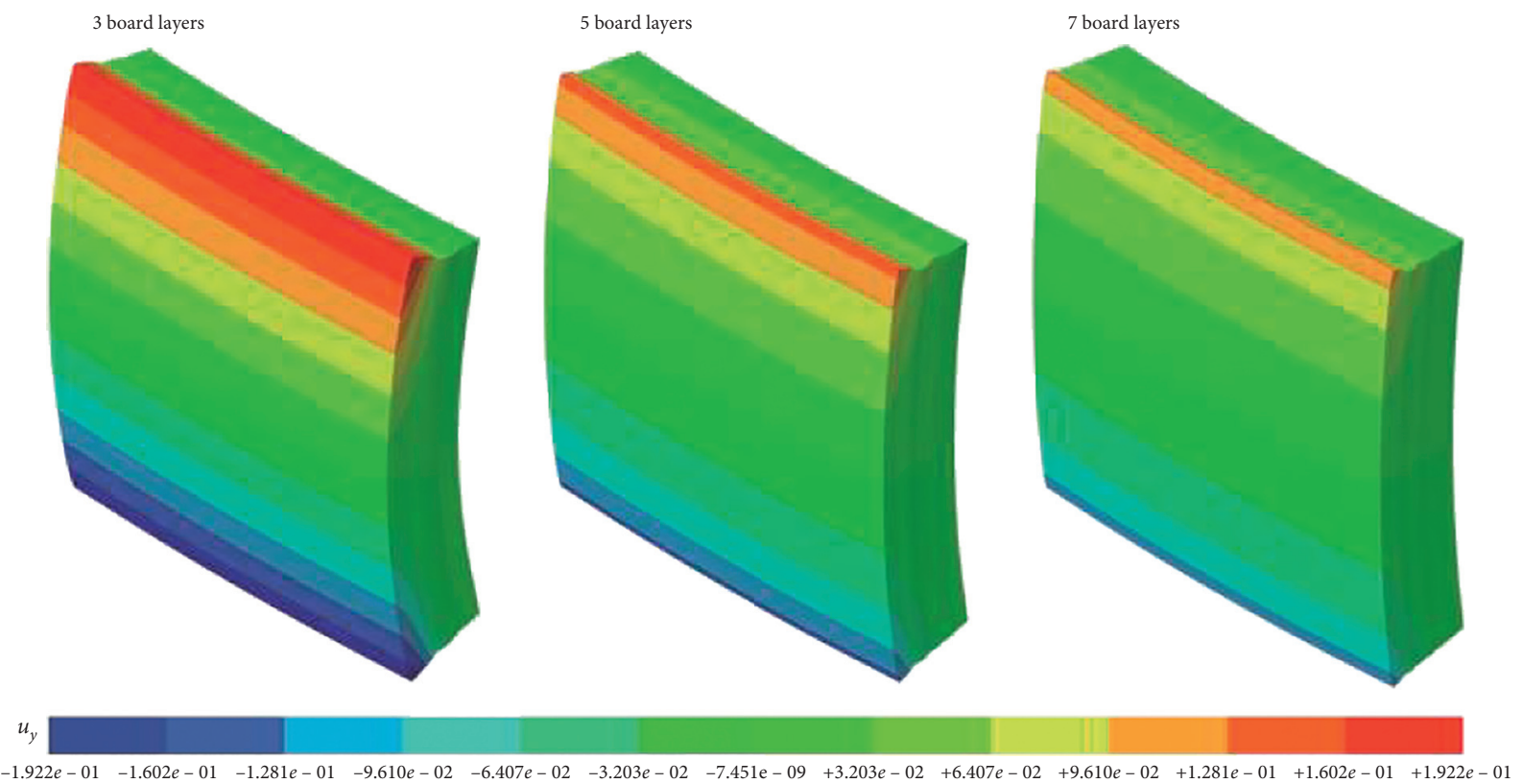

(b)

FIgURE 5: Continued. 


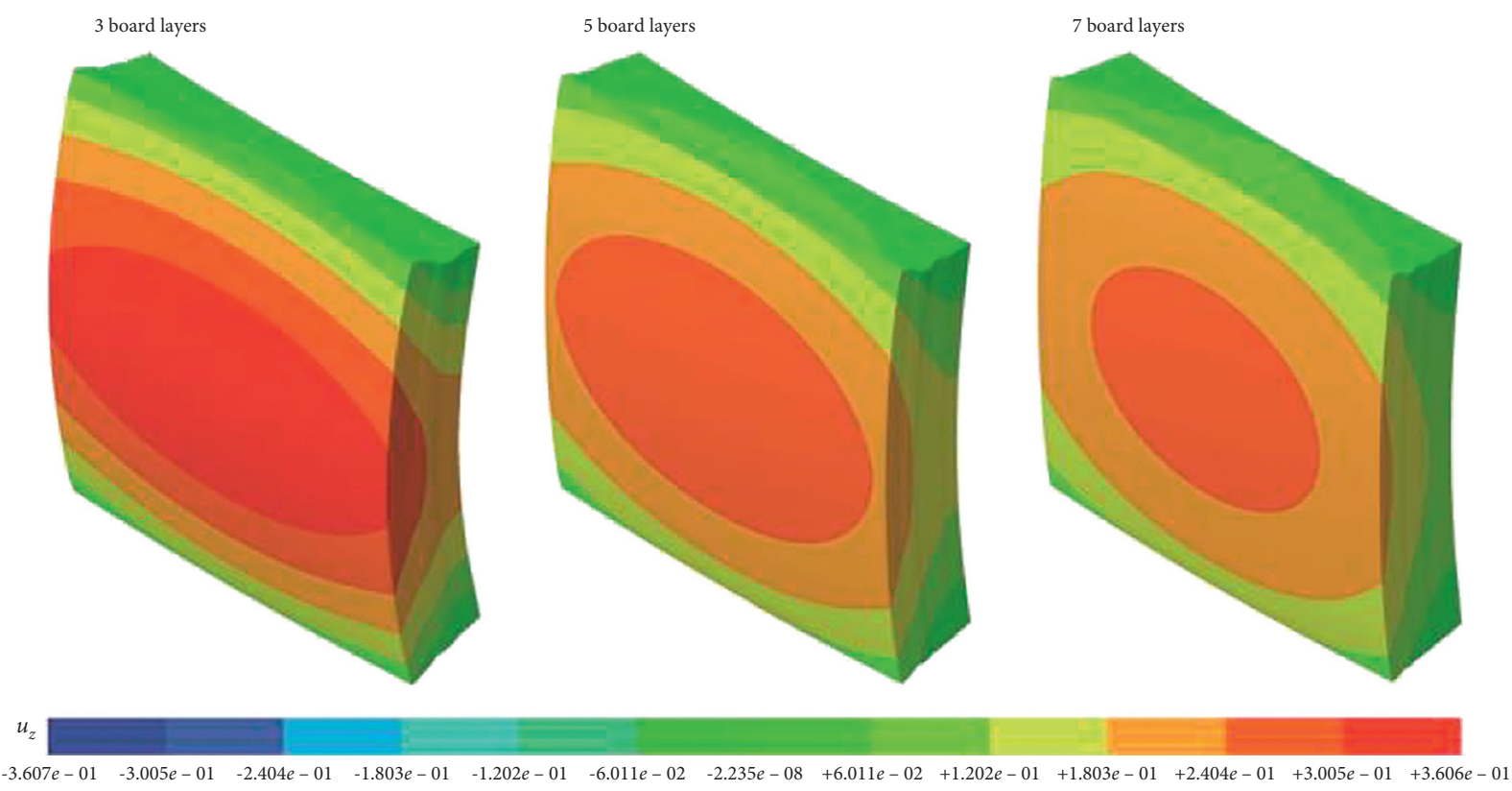

(c)

Figure 5: The deformations of the CLT plate with various layer components in $x, y$, and $z$ coordinate directions. (a) $u_{x}$ displacement; (b) $u_{y}$ displacement; (c) $u_{z}$ displacement.

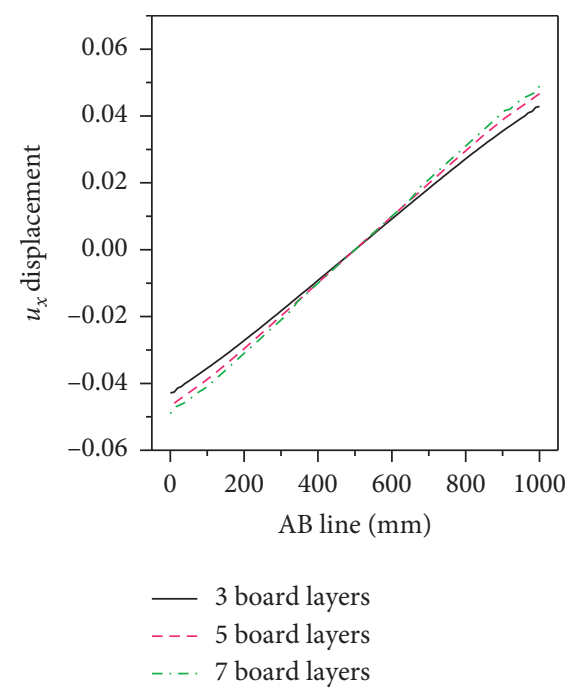

(a)

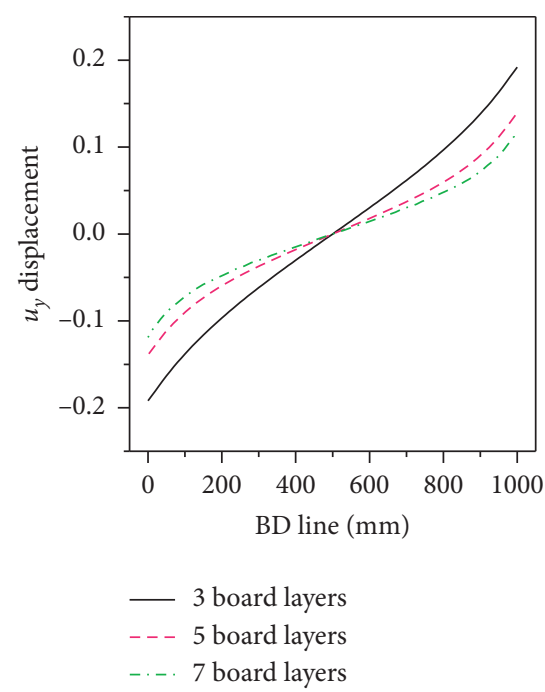

(b)

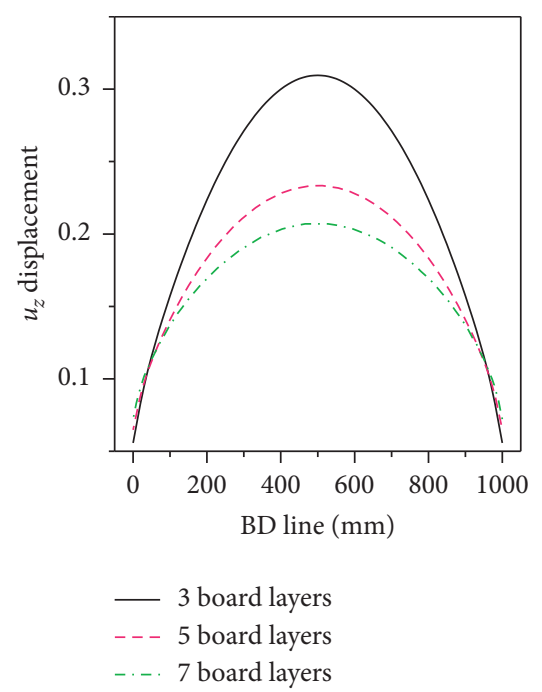

(c)

FIgURE 6: The displacement distributions along the CLT plate borderlines. (a) $u_{x}$ displacement of $A B$ line; (b) $u_{y}$ displacement of $B D$ line; (c) $u_{z}$ displacement of $B D$ line. 


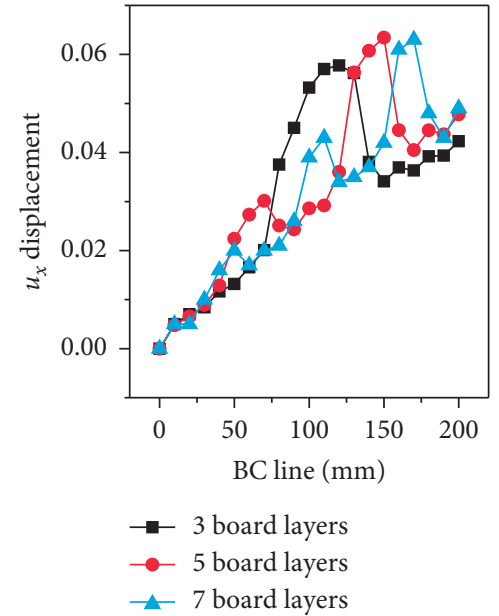

(a)

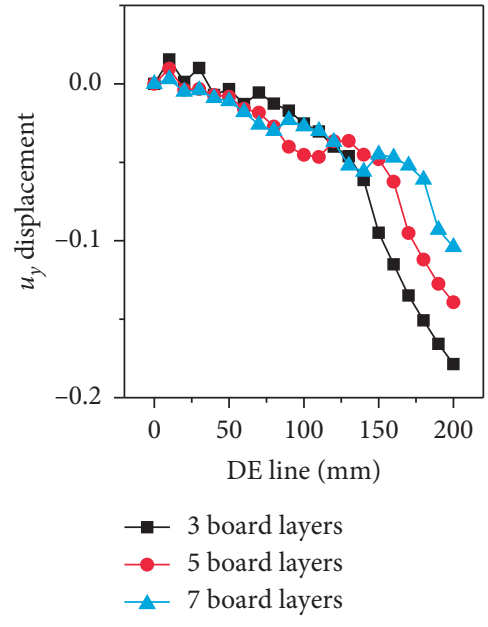

(b)

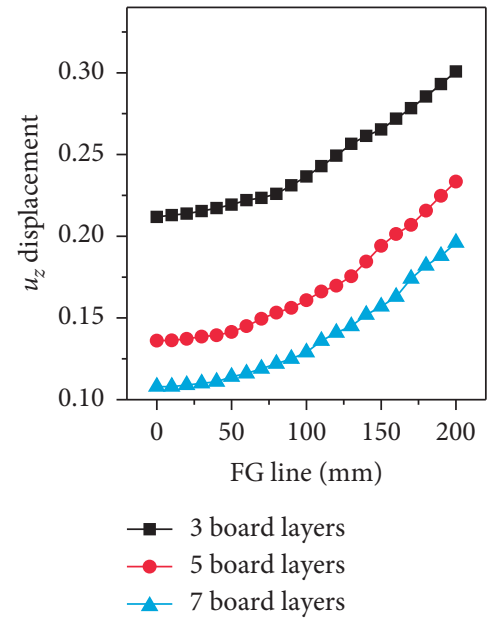

(c)

Figure 7: The displacement distributions along the CLT plate thickness direction. (a) $u_{x}$ displacement of $B C$ line; (b) $u_{y}$ displacement of $D E$ line; (c) $u_{z}$ displacement of $F G$ line.

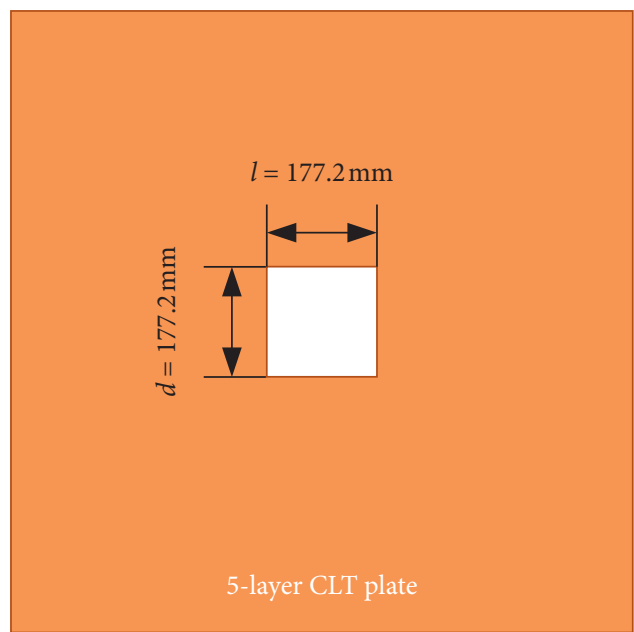

(a)

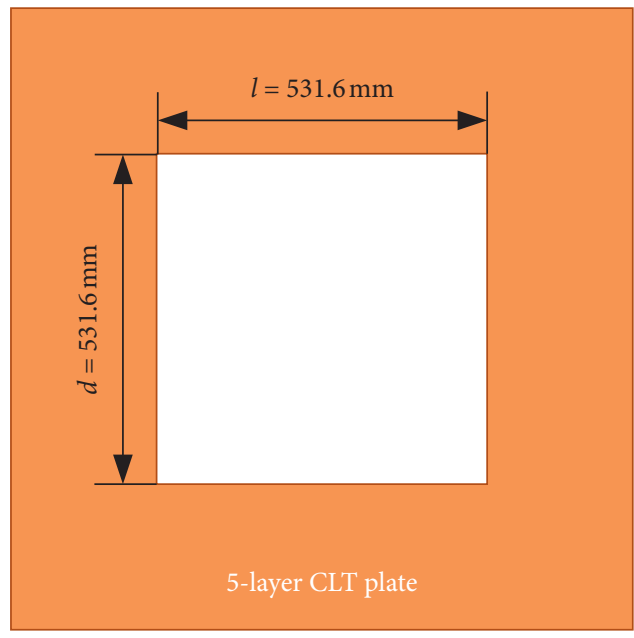

(c)

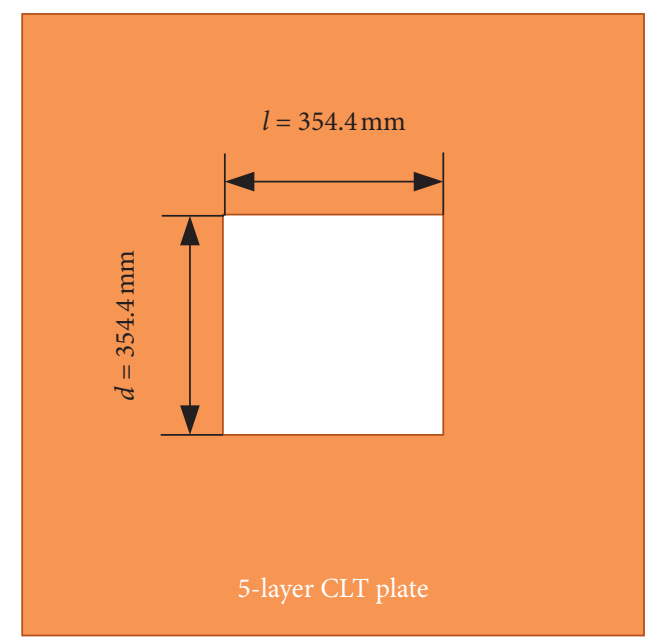

(b)

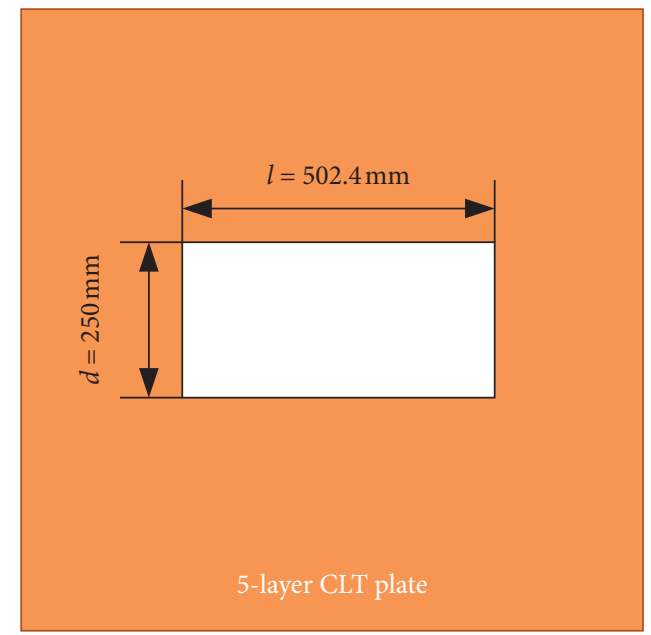

(d)

FIgURE 8: Continued. 


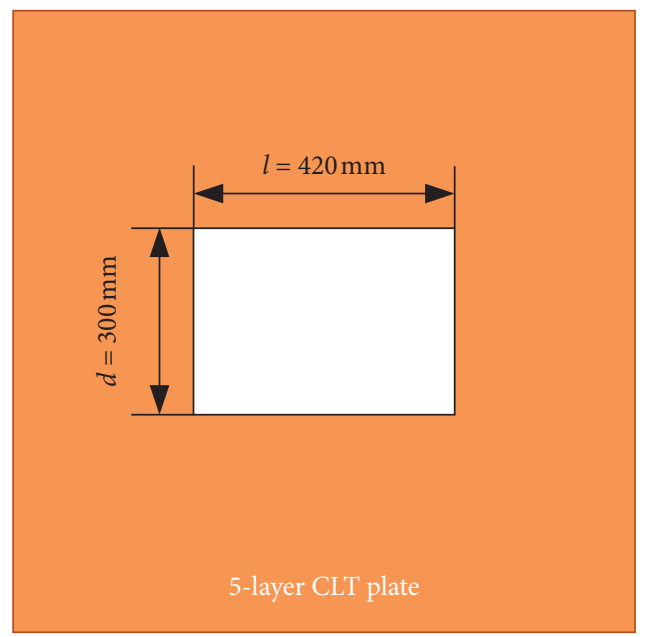

(e)

FIGURE 8: The CLT plate with five kinds of square hole dimension. (a) $l=d=77.2 \mathrm{~mm}$; (b) $l=d=354.4 \mathrm{~mm}$; (c) $l=d=531.6 \mathrm{~mm}$; (d) $l=502.4 \mathrm{~mm}, d=250 \mathrm{~mm}$; (e) $l=420 \mathrm{~mm}, d=300 \mathrm{~mm}$.
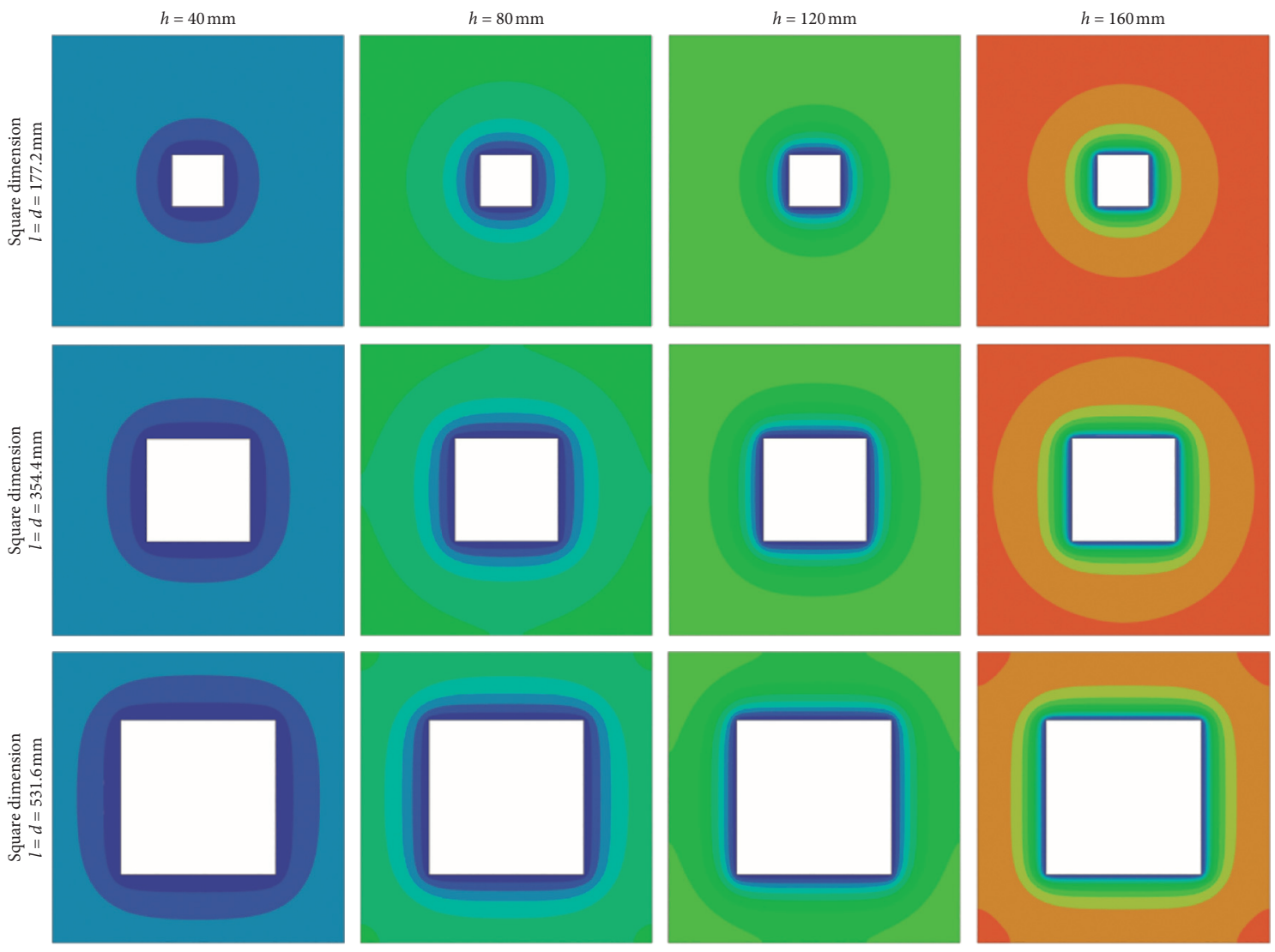

$-2.731 e+02-2.715 e+02-2.699 e+02-2.683 e+02-2.666 e+02-2.650 e+02-2.634 e+02-2.618 e+02-2.601 e+02-2.585 e+02-2.569 e+02-2.553 e+02-2.537 e+02$

FIGURE 9: The temperature distribution of the CLT plate with various central hole dimension at depth positions $h=40 \mathrm{~mm}, 80 \mathrm{~mm}, 120 \mathrm{~mm}$, and $160 \mathrm{~mm}$. 


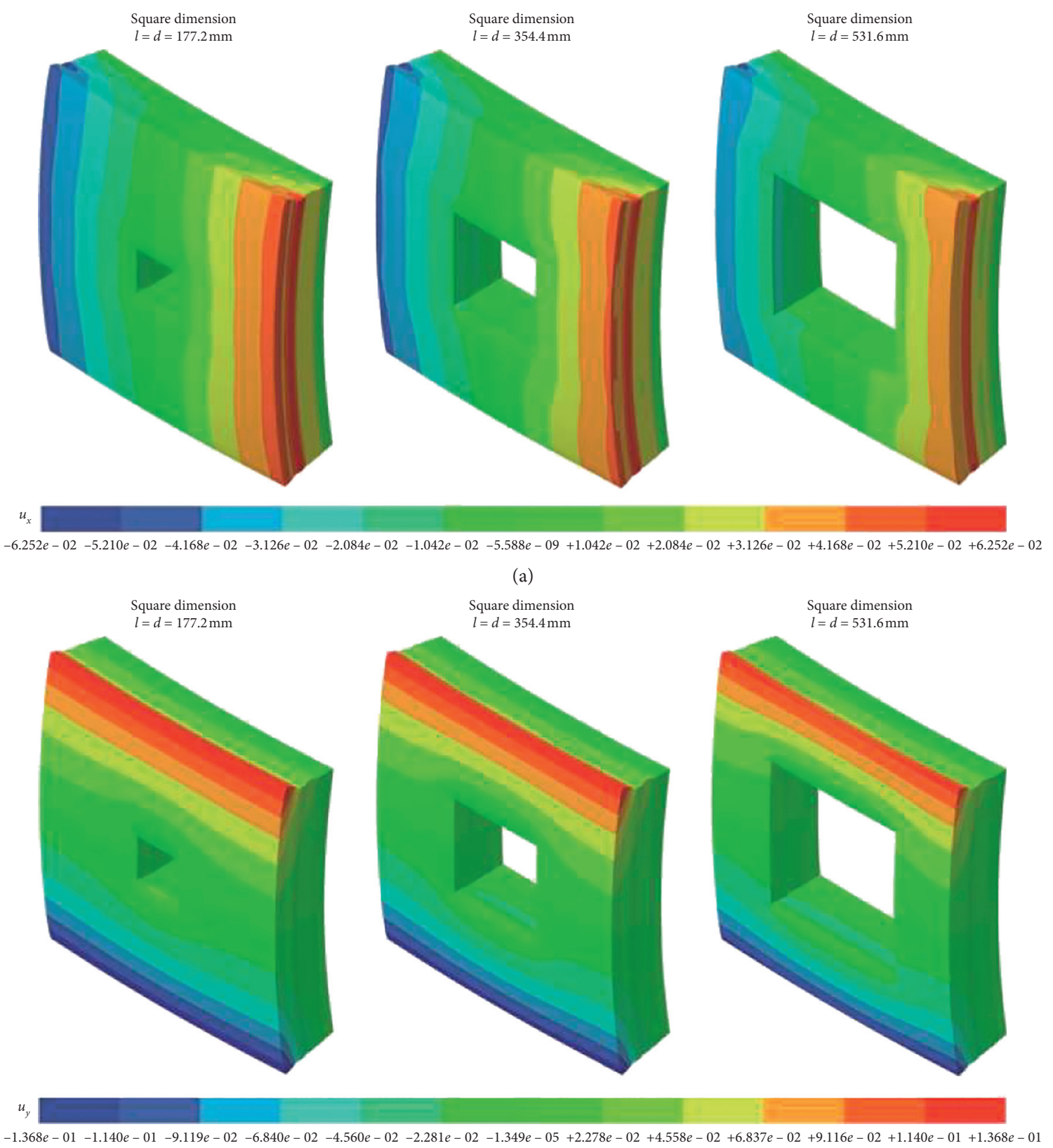

(b)

Figure 10: Continued. 


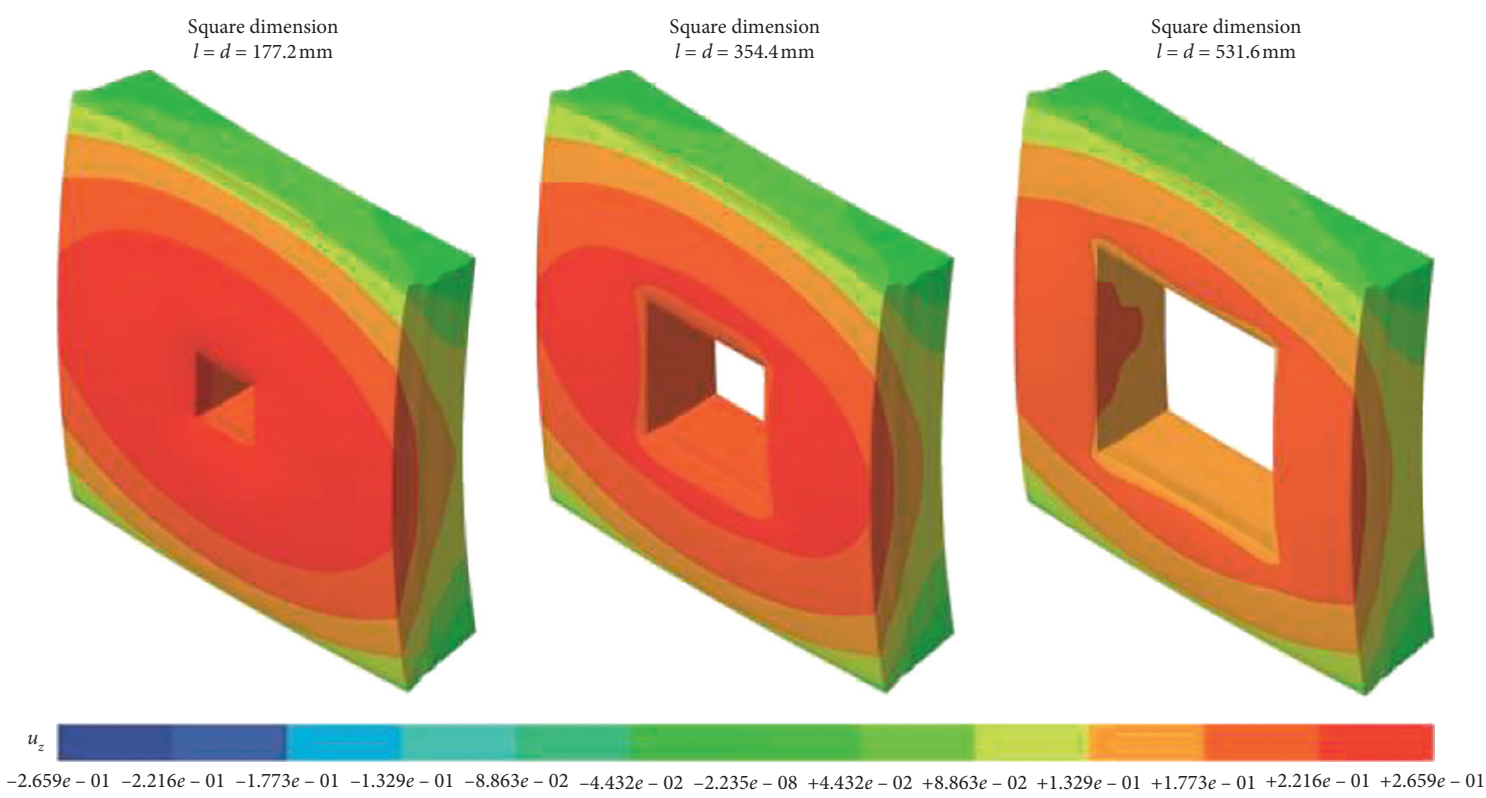

(c)

FIGURE 10: The deformations of the CLT plate with various central hole dimensions in $x, y$, and $z$ coordinate directions. (a) $u_{x}$ displacement; (b) $u_{y}$ displacement; (c) $u_{z}$ displacement.
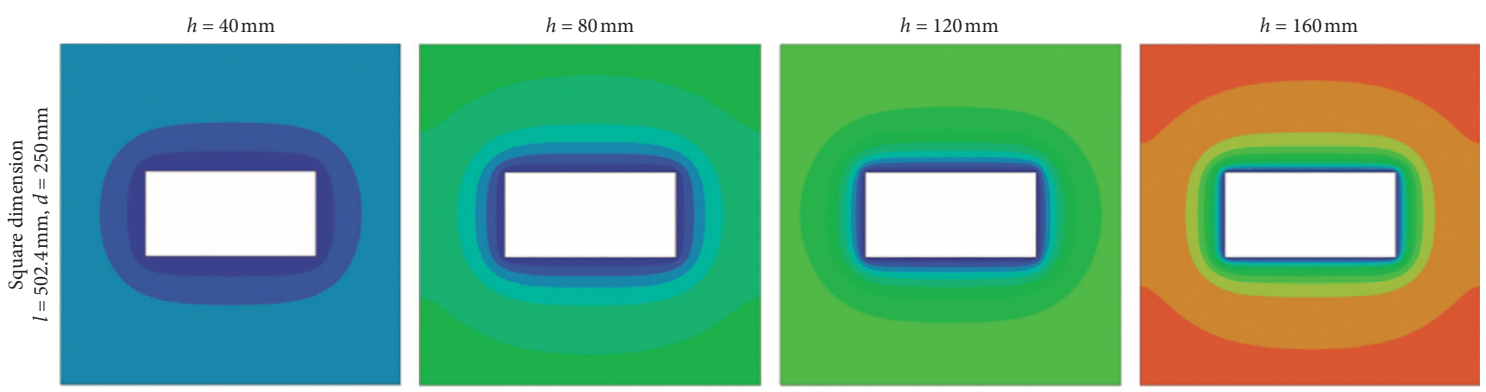

$-2.731 e+02-2.715 e+02-2.699 e+02-2.683 e+02-2.666 e+02-2.650 e+02-2.634 e+02-2.618 e+02-2.601 e+02-2.585 e+02-2.569 e+02-2.553 e+02-2.537 e+02$

(a)
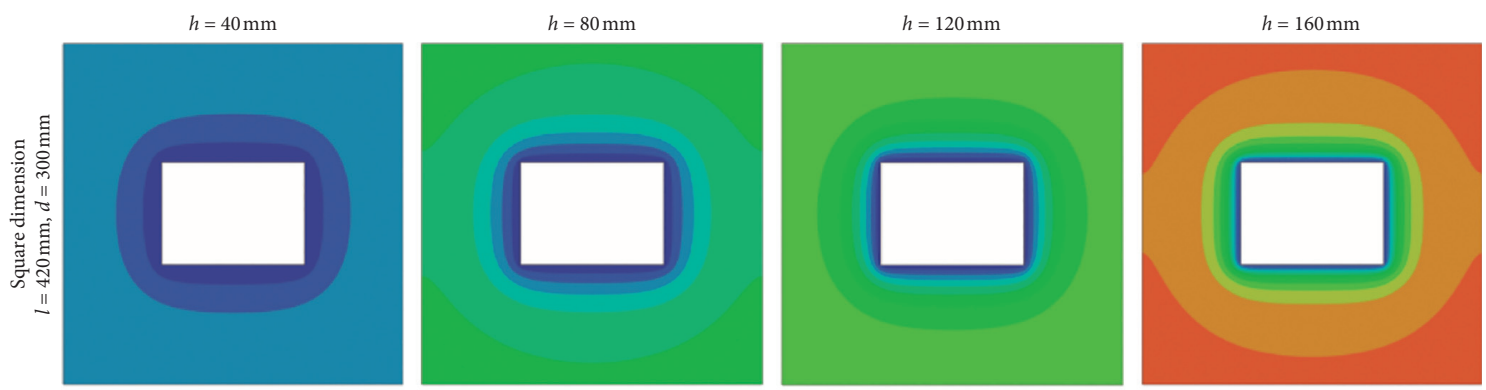

$-2.731 e+02-2.715 e+02-2.699 e+02-2.683 e+02-2.666 e+02-2.650 e+02-2.634 e+02-2.618 e+02-2.601 e+02-2.585 e+02-2.569 e+02-2.553 e+02-2.537 e+02$

(b)

FIGURE 11: The temperature distribution of the CLT plate with two different square hole dimensions at depth positions $h=40 \mathrm{~mm}, 80 \mathrm{~mm}$, $120 \mathrm{~mm}$, and $160 \mathrm{~mm}$. 

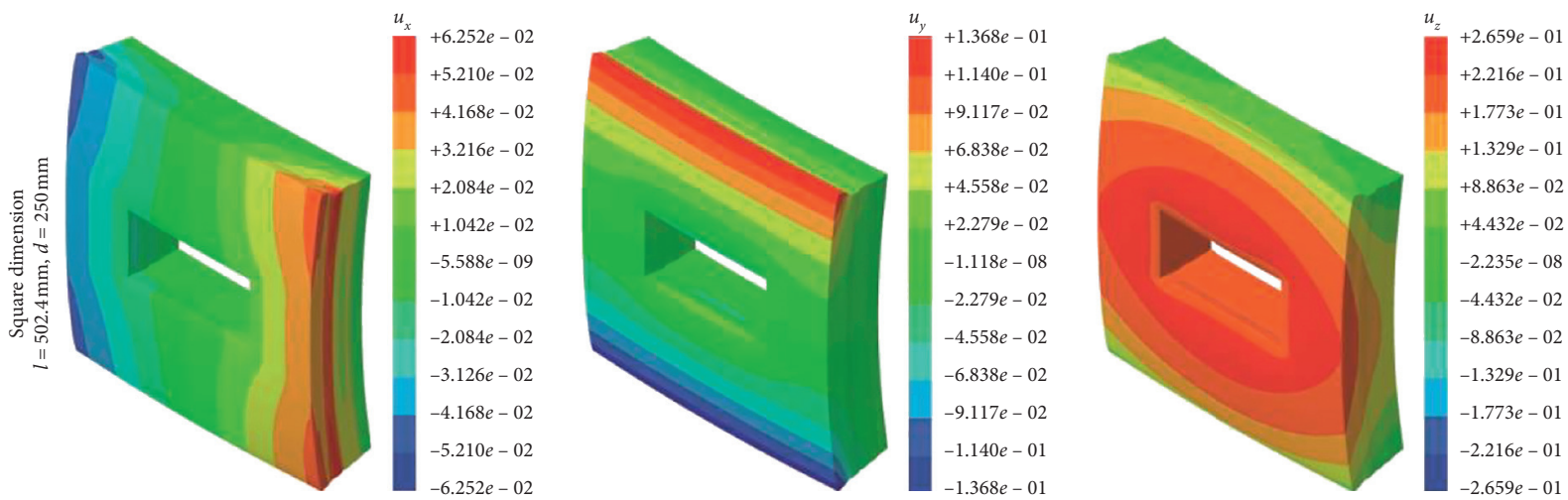

(a)
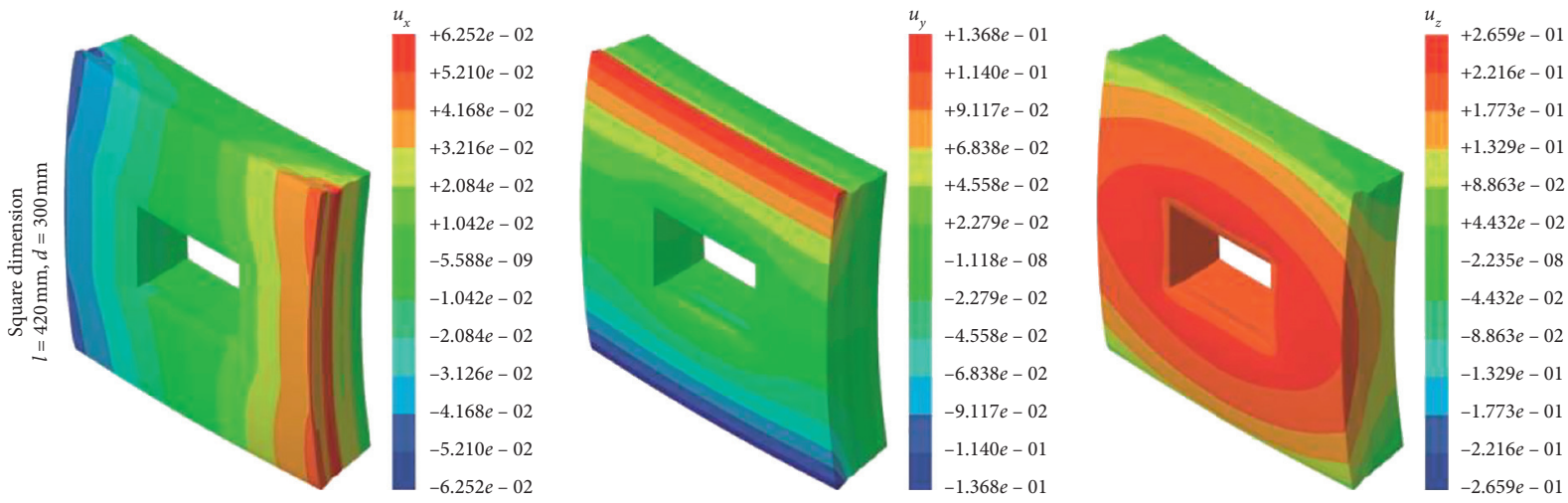

(b)

Figure 12: The deformations of the CLT plate with two different square hole dimensions in $x, y$, and $z$ coordinate directions. (a) $u_{x}$ displacement; (b) $u_{y}$ displacement; (c) $u_{z}$ displacement.

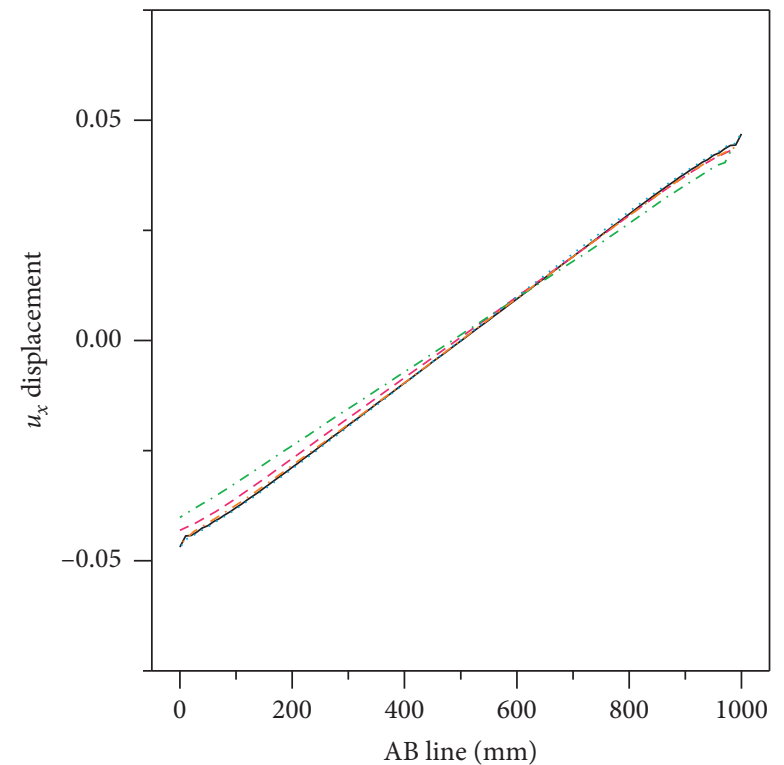
- Square dimension $l=d=177.2 \mathrm{~mm}$
- - - Square dimension $l=d=354.4 \mathrm{~mm}$
... Square dimension $l=d=531.6 \mathrm{~mm}$
Square dimension $l=$ $502.4 \mathrm{~mm}, d=250 \mathrm{~mm}$
-... Square dimension $l=$ $420 \mathrm{~mm}, d=300 \mathrm{~mm}$

(a)

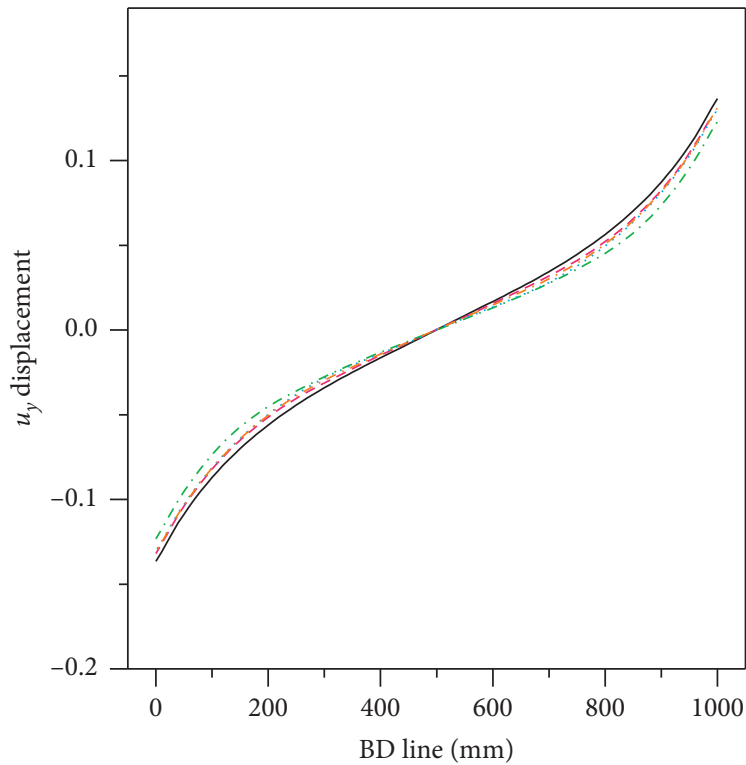

- Square dimension …. Square dimension $l=$ $l=d=177.2 \mathrm{~mm}$ $502.4 \mathrm{~mm}, d=250 \mathrm{~mm}$

-.- Square dimension _... Square dimension $l=$ $l=d=354.4 \mathrm{~mm} \quad 420 \mathrm{~mm}, d=300 \mathrm{~mm}$

-... Square dimension $l=d=531.6 \mathrm{~mm}$

(b)

Figure 13: Continued. 


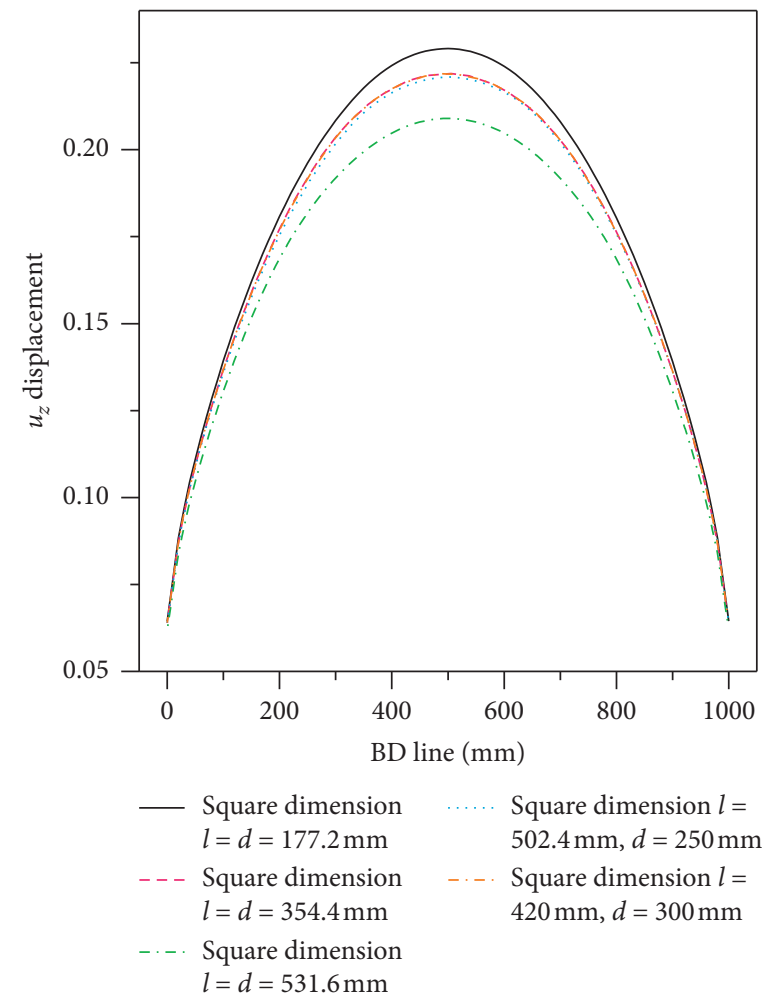

(c)

Figure 13: The displacement distributions along the CLT plate borderlines. (a) $u_{x}$ displacement of $A B$ line; (b) $u_{y}$ displacement of $B D$ line; (c) $u_{z}$ displacement of $B D$ line.

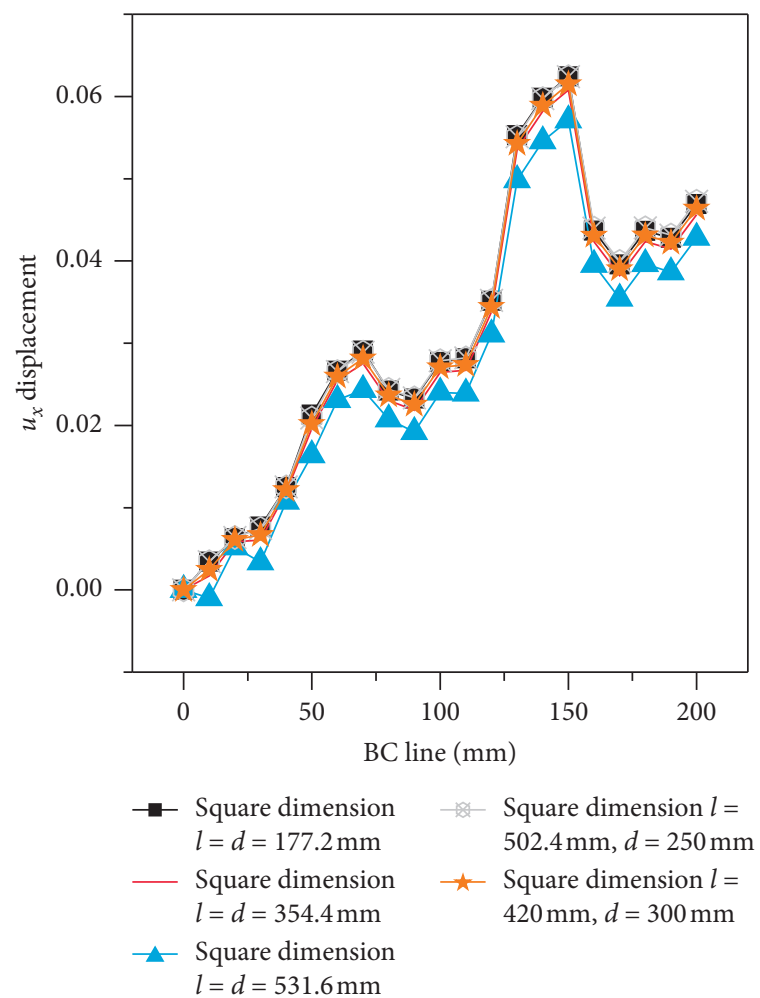

(a)

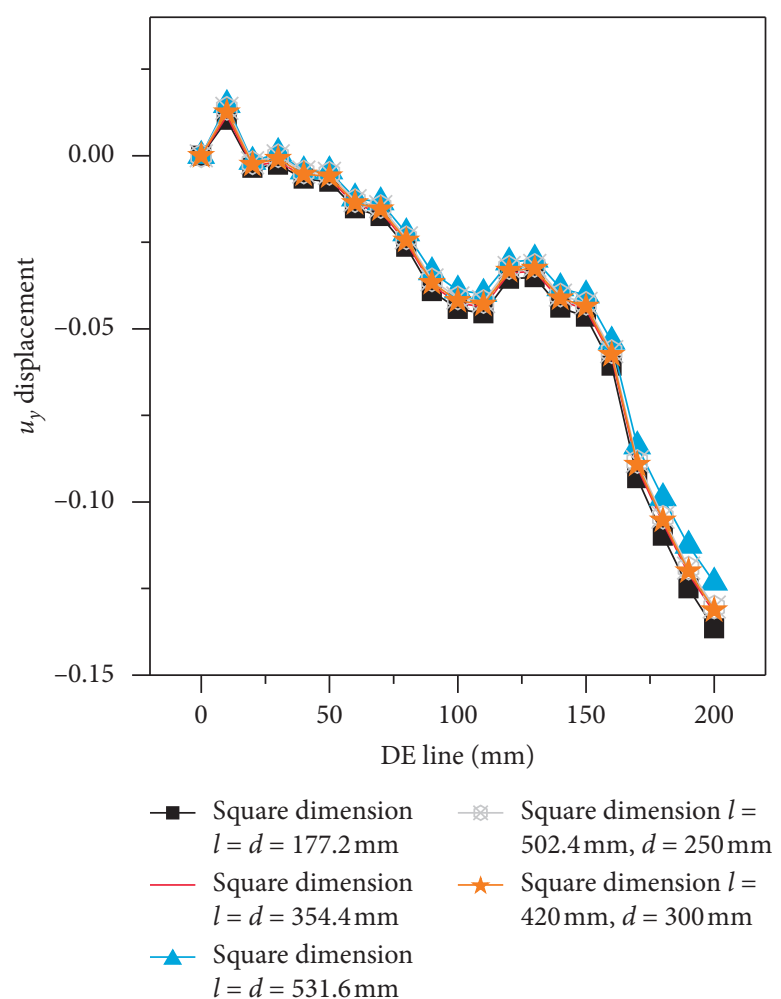

(b)

FIgURe 14: Continued. 


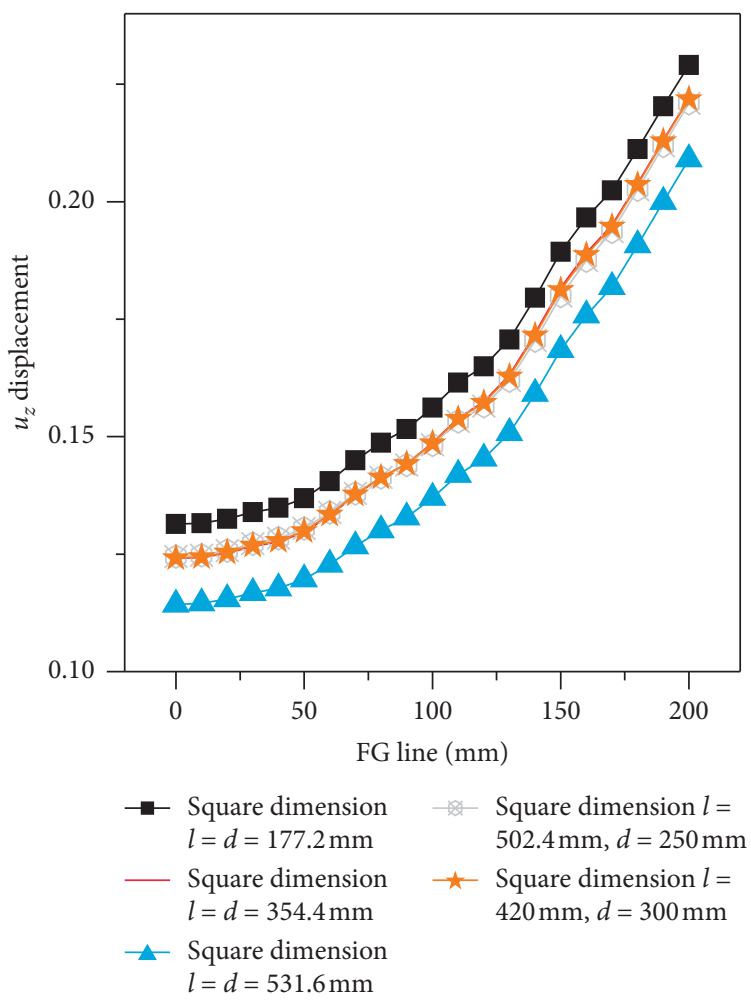

(c)

FIgURE 14: The displacement distributions along the CLT plate thickness direction. (a) $u_{x}$ displacement of $B C$ line; (b) $u_{y}$ displacement of $D E$ line; (c) $u_{z}$ displacement of $F G$ line.

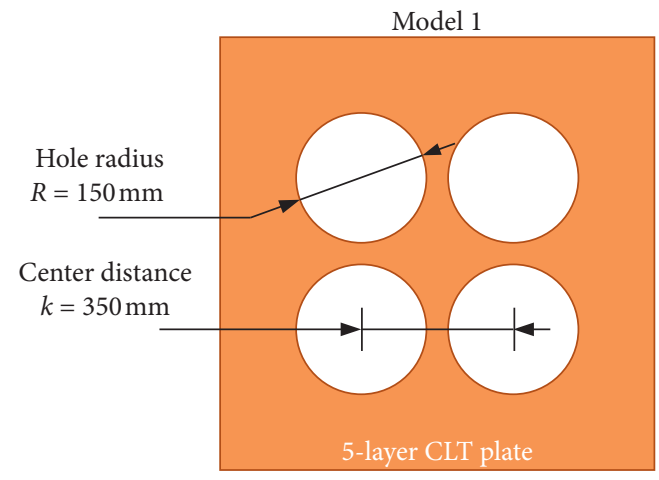

(a)

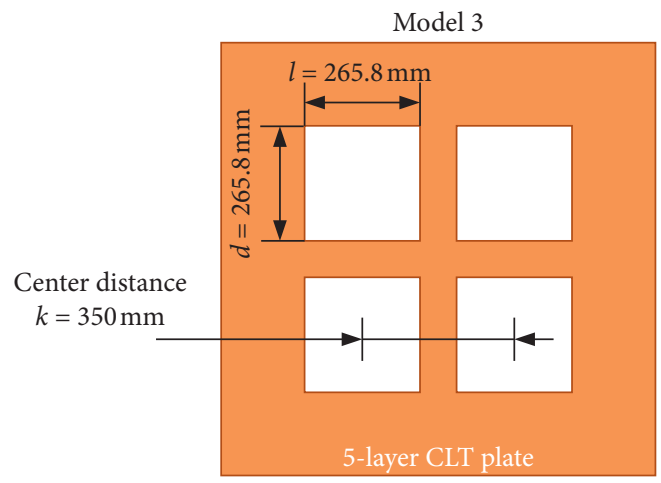

(c)

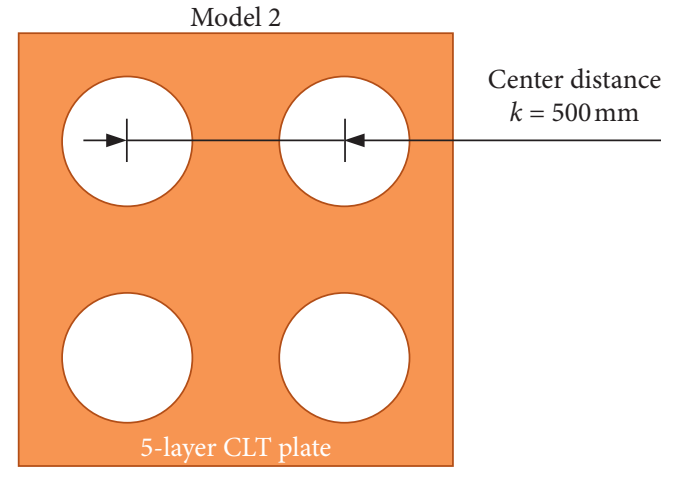

(b)

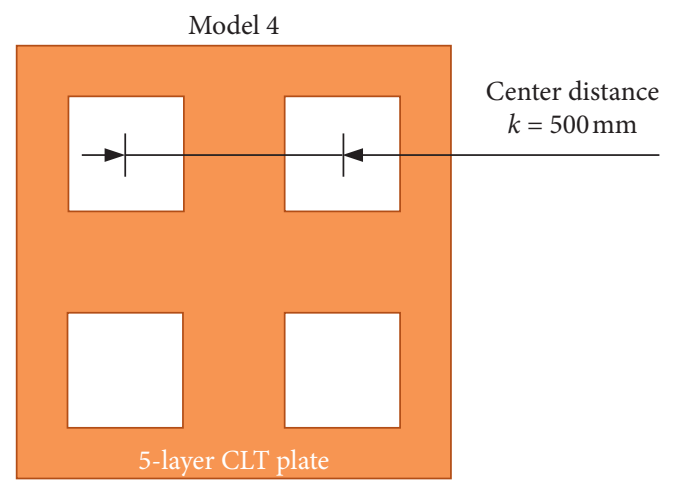

(d)

FIGURE 15: The CLT plate in four model compositions, the holes were located in different central distances and forms. (a) Four round holes in central distance $k=350 \mathrm{~mm}$; (b) four round hole in central distance $k=500 \mathrm{~mm}$; (c) four square hole in central distance $k=350 \mathrm{~mm}$; (d) four square hole in central distance $k=500 \mathrm{~mm}$. 

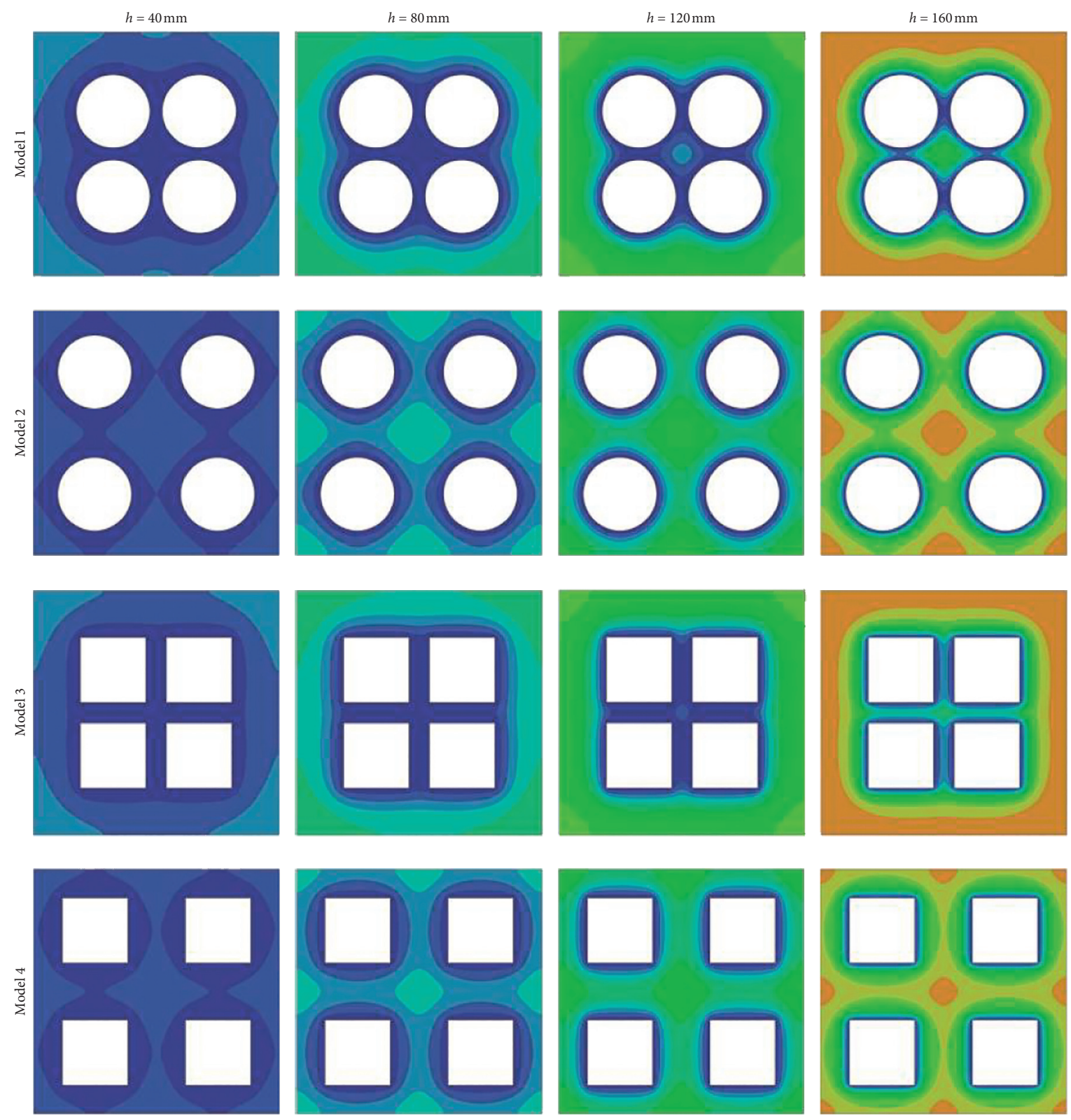

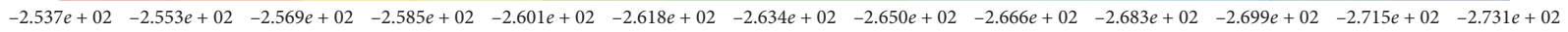

FIGURE 16: The temperature distribution of the CLT plate in four model compositions at depth positions $h=40 \mathrm{~mm}, 80 \mathrm{~mm}, 120 \mathrm{~mm}$, and $160 \mathrm{~mm}$. 


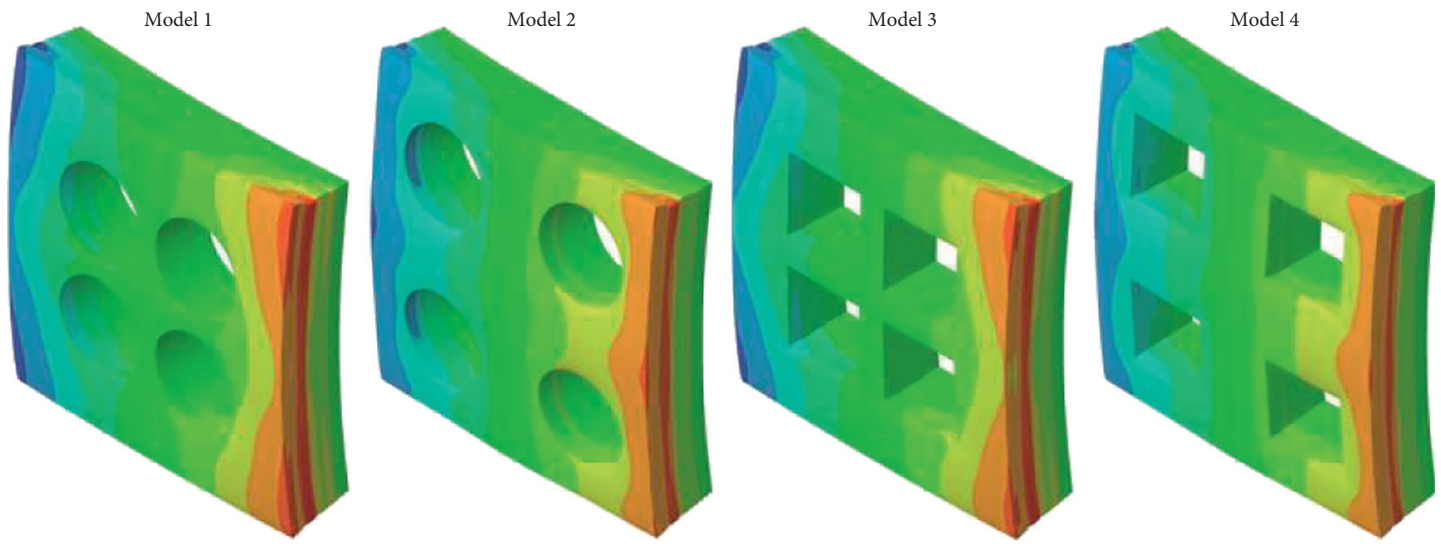

$u_{x}$

$-5.418 e-02-4.516 e-02-3.613 e-02-2.710 e-02-1.807 e-02-9.047 e-03-2.005 e-05+9.007 e-03+1.803 e-02+2.706 e-02+3.609 e-02+4.512 e-02+5.414 e-02$

(a)

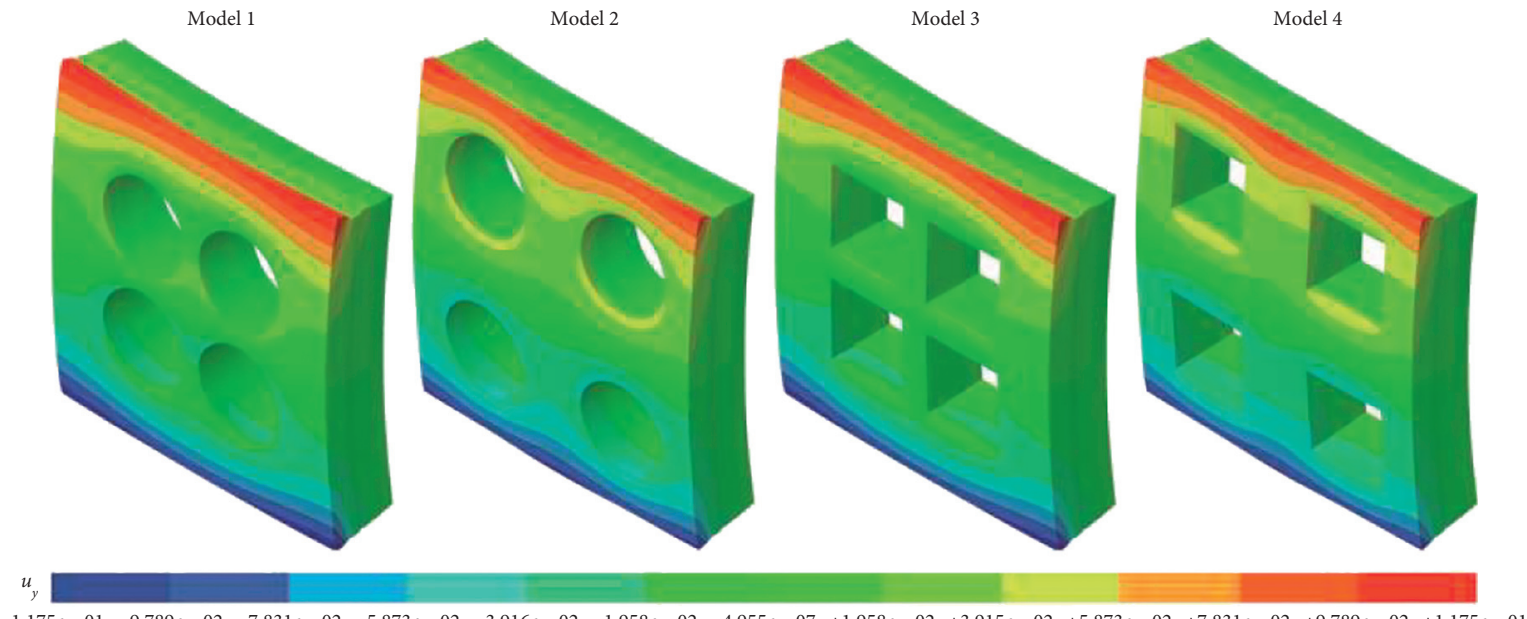

$-1.175 e-01-9.789 e-02-7.831 e-02-5.873 e-02-3.916 e-02-1.958 e-02-4.955 e-07+1.958 e-02+3.915 e-02+5.873 e-02+7.831 e-02+9.789 e-02+1.175 e-01$

(b)

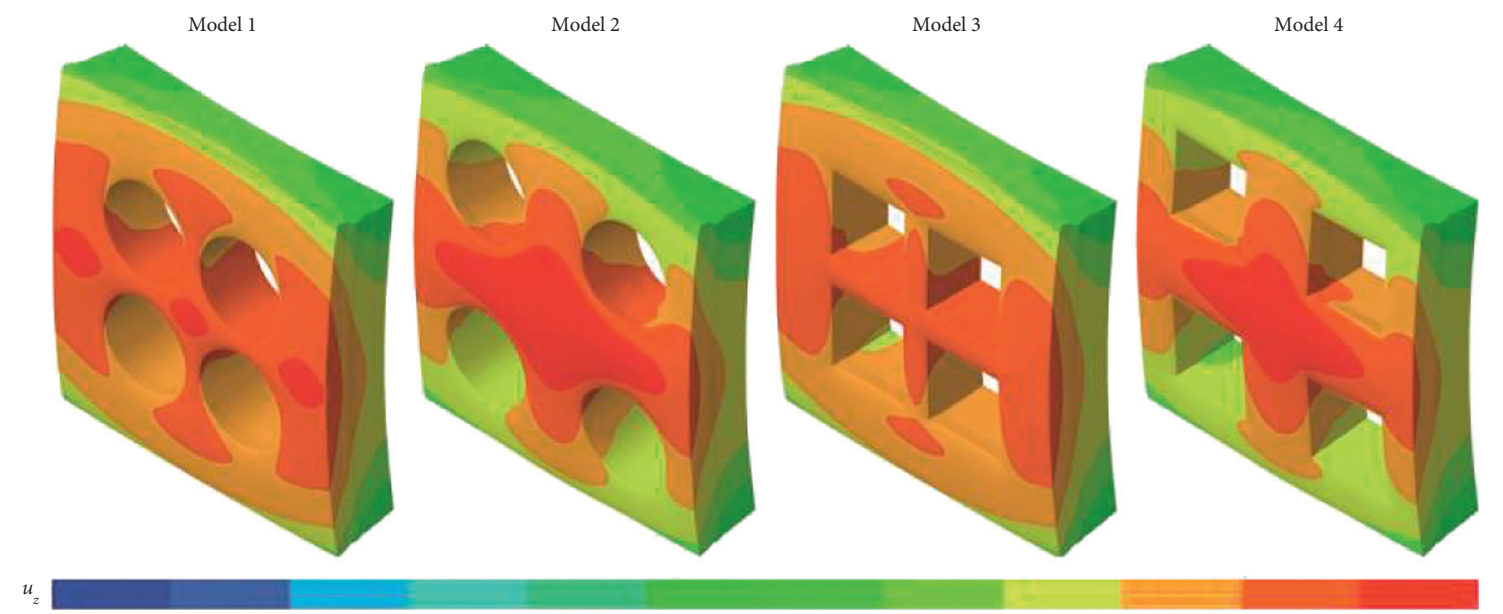

$-2.405 e-01-2.004 e-01-1.603 e-01-1.203 e-02-8.017 e-02-4.009 e-02-7.451 e-09+4.009 e-02+8.017 e-02+1.203 e-02+1.603 e-01+2.004 e-01+2.405 e-01$

(c)

FIgURE 17: The deformations of the CLT plate in four model compositions in $x, y$, and $z$ coordinate directions. (a) $u_{x}$ displacement; (b) $u_{y}$ displacement; (c) $u_{z}$ displacement. 


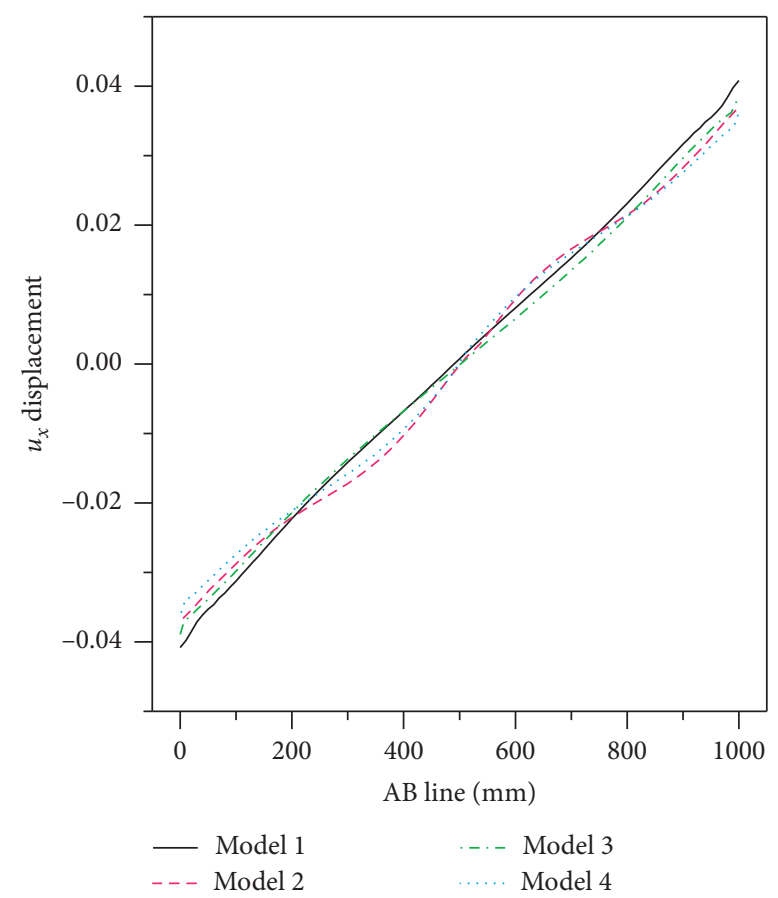

(a)

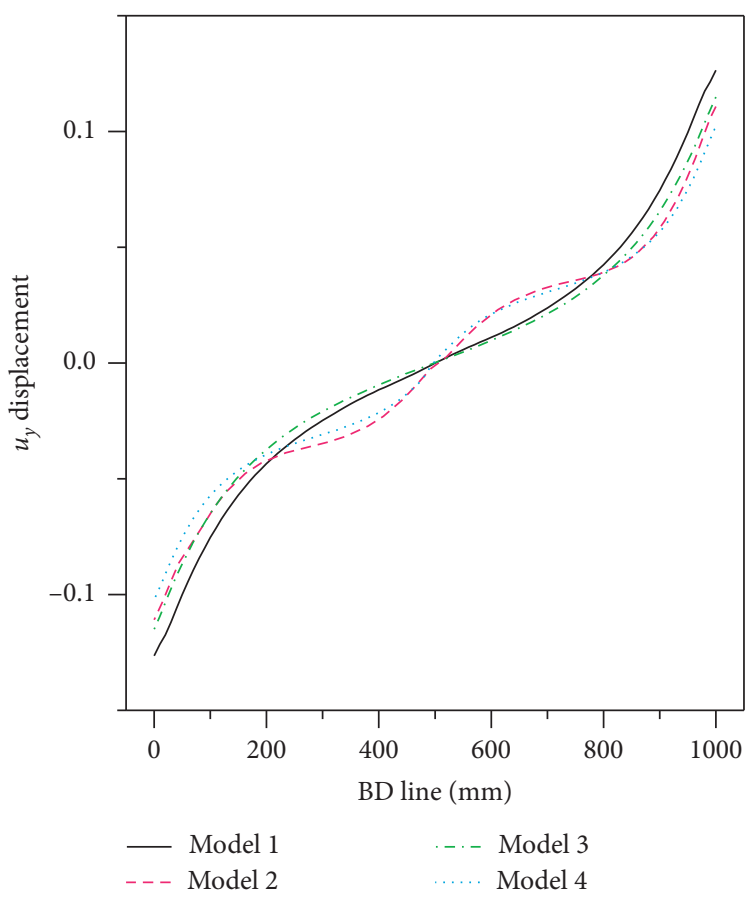

(b)

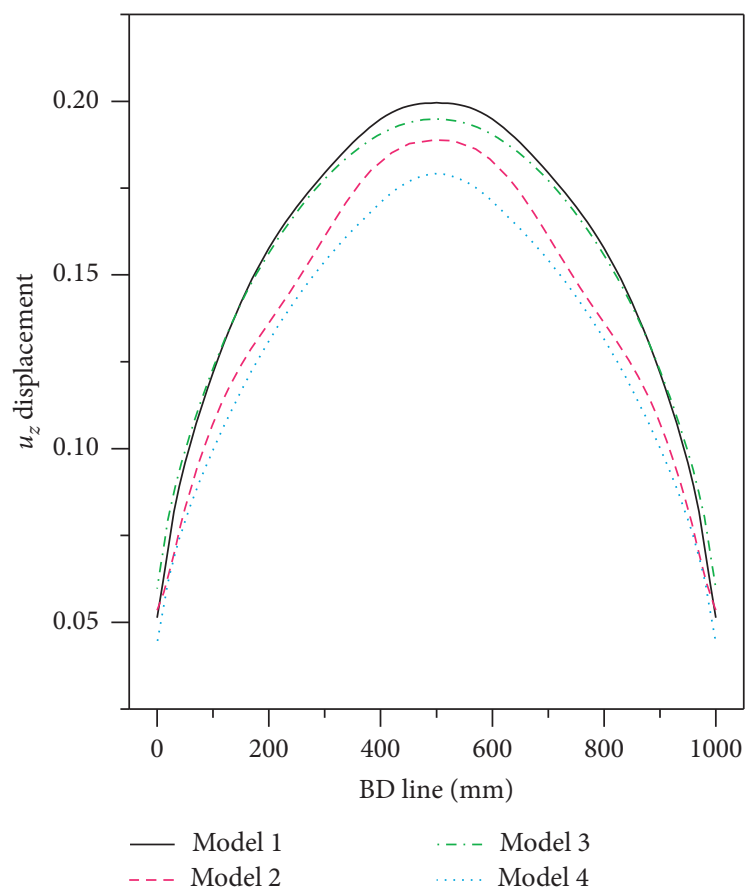

(c)

FIgURE 18: The displacement distributions along the CLT plate borderlines. (a) $u_{x}$ displacement of $A B$ line; (b) $u_{y}$ displacement of $B D$ line; (c) $u_{z}$ displacement of $B D$ line. 


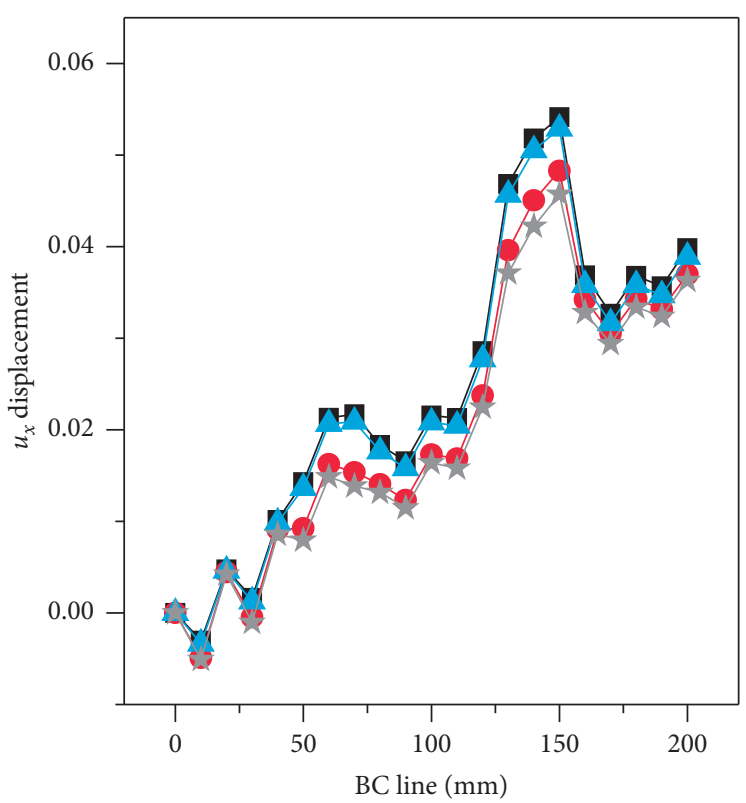

Model 1

Model 2

- Model 3
+- Model 4

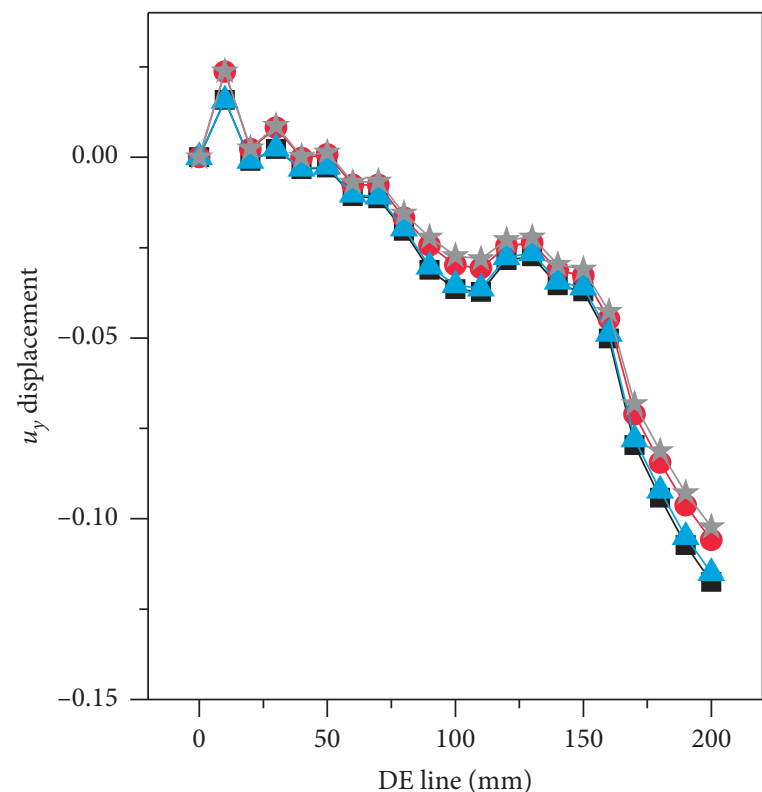

Model 1

Model 2

- Model 3
+ Model 4

(b)

(a)

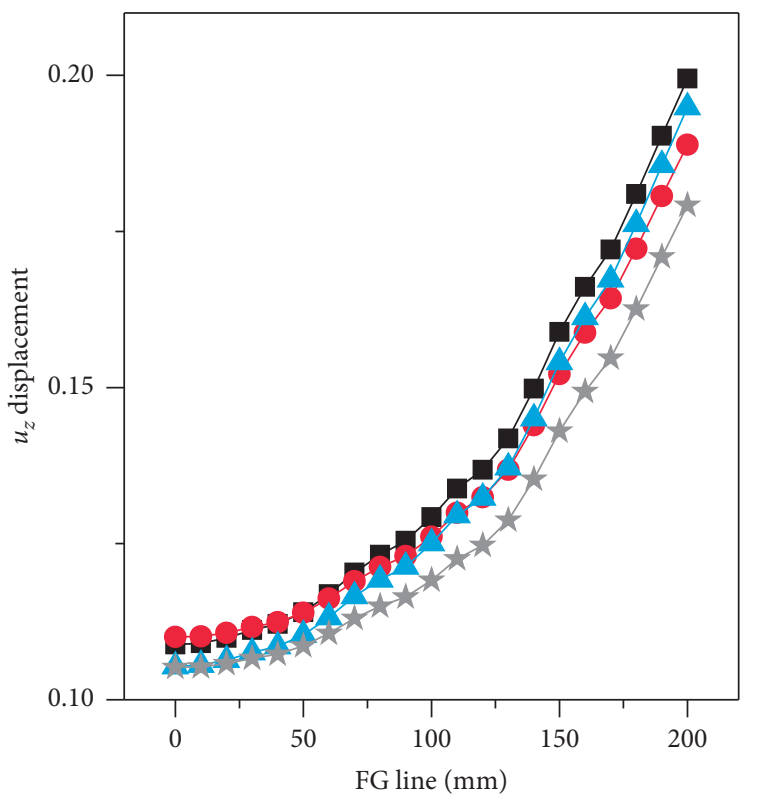

Model 1

Model 2

$$
\begin{array}{r}
\triangle \text { Model } 3 \\
\star \quad \text { Model } 4
\end{array}
$$

(c)

FIGURE 19: The displacement distributions along the CLT plate thickness direction. (a) $u_{x}$ displacement of $B C$ line; (b) $u_{y}$ displacement of $D E$ line; (c) $u_{z}$ displacement of $F G$ line. 


\section{Conclusions}

This paper presented the CLT structural behavior in hightemperature environment via the well-known FEM. The basic equations for the CLT material were given. The temperature distribution and the structural deformation were demonstrated. Several numerical models were built for analyzing different impact factors. A CLT plate was established to investigate the board layer number influence, central hole dimension, conformation influences and hole position influence.

We have compared the results with the reference paper, and the great agreement verified the correctness of the FEM calculation process. Board layer plays a significant influence on the performance of CLT plate. With the change of layer, the temperature distributions of the plate and displacement in all coordinate directions have changed dramatically. In terms of other impact factors, from the contour plots of the temperature and displacements, we can notice these factors actually bring effect on the CLT plate, but from the displacement distribution in all coordinate directions along the borderline and thickness, these factors are not as obvious as the number of plate layers. And the $u_{z}$ displacement component was more sensitive to the influence factors. The investigation of CLT structures brings reference data for the application of CLT material.

\section{Data Availability}

The data supporting the conclusions of the study are present in the manuscript.

\section{Conflicts of Interest}

The authors declare that they have no conflicts of interest.

\section{Acknowledgments}

The authors would like to acknowledge the financial support from Chinese Universities Scientific Fund, no. 300102218214 and Chinese Universities Scientific Fund, no. 300102219211.

\section{References}

[1] A. J. Barotto, S. Monteoliva, J. Gyenge, A. Martinez-Meier, and M. E. Fernandez, "Functional relationships between wood structure and vulnerability to xylem cavitation in races of Eucalyptus globulus differing in wood density," Tree Physiology, vol. 38, no. 2, pp. 243-251, 2018.

[2] C. Chen, D. Tu, Q. Zhou et al., "Development and evaluation of a surface-densified wood composite with an asymmetric structure," Construction and Building Materials, vol. 242, Article ID 118007, 2020.

[3] E. S. Flores, I. Dayyani, R. M. Ajaj et al., "Analysis of crosslaminated timber by computational homogenisation and experimental validation," Composite Structures, vol. 121, pp. 386-394, 2015.

[4] Y. Jiang and R. Crocetti, "CLT-concrete composite floors with notched shear connectors," Construction and Building Materials, vol. 195, pp. 127-139, 2019.
[5] A. Hassanieh, H. R. Valipour, and M. A. Bradford, "Composite connections between CLT slab and steel beam: experiments and empirical models," Journal of Constructional Steel Research, vol. 138, pp. 823-836, 2017.

[6] L.-M. Ottenhaus, M. Li, and T. Smith, "Structural performance of large-scale dowelled CLT connections under monotonic and cyclic loading," Engineering Structures, vol. 176, pp. 41-48, 2018.

[7] E. Eurocode, 2: Design of Concrete Structures-Part 1-2: General Rules-Structural Fire Design, European Concrete Platform, Brussels, Belgium, 2004.

[8] M. Fragiacomo, A. Menis, I. Clemente, G. Bochicchio, and A. Ceccotti, "Fire resistance of cross-laminated timber panels loaded out of plane," Journal of Structural Engineering, vol. 139, no. 12, Article ID 04013018, 2013.

[9] M. Klippel, J. Schmid, A. Frangi, and G. Fink, "Fire Design of glued-laminated timber beams with regard to the adhesive performance using the reduced cross-section method,"vol. 2014, pp. 339-348, in Proceedings of the 1st Meeting of the International Network on Timber Engineering Research (INTER 2014), vol. 2014, pp. 339-348, Timber Scientific Publishing, KIT Holzbau und Baukonstruktionen, Bath, UK, September 2004.

[10] M. Klippel, Fire Safety of Bonded Structural Timber Elements, ETH Zurich, Zürich, Switzerland, 2014.

[11] J. Schmid, J. König, and J. Köhler, "Fire-exposed cross-laminated timber-modelling and tests," in Proceedings of the World Conference on Timber Engineering, Trentino, Italy, June 2010.

[12] J. Schmid, M. Klippel, A. Just, A. Frangi, and M. Tiso, "Simulation of the fire resistance of cross-laminated timber (CLT)," Fire Technology, vol. 54, no. 5, pp. 1113-1148, 2018.

[13] J. Schmid, N. Werther, M. Klippel, and A. Frangi, "Structural fire design-statement on the design of cross-laminated timber (CLT)," Civil Engineering Research Journal, vol. 7, no. 5, pp. 113-117, 2019.

[14] A. Frangi, M. Fontana, E. Hugi, and R. Jübstl, "Experimental analysis of cross-laminated timber panels in fire," Fire Safety Journal, vol. 44, no. 8, pp. 1078-1087, 2009.

[15] A. Frangi, M. Fontana, M. Knobloch, and G. Bochicchio, "Fire behaviour of cross-laminated solid timber panels," Fire Safety Science, vol. 9, pp. 1279-1290, 2008.

[16] Y. Wang, J. Zhang, F. Mei, J. Liao, and W. Li, "Experimental and numerical analysis on fire behaviour of loaded crosslaminated timber panels," Advances in Structural Engineering, vol. 23, no. 1, pp. 22-36, 2020.

[17] C. Bedon and M. Fragiacomo, "Fire resistance of in-plane compressed log-house timber walls with partial thermal insulation," Buildings, vol. 8, no. 10, p. 131, 2018.

[18] C. H. Luce and B. C. Wemple, "Introduction to special issue on hydrologic and geomorphic effects of forest roads," Earth Surface Processes and Landforms, vol. 26, no. 2, pp. 111-113, 2001.

[19] E. I. S. Flores, K. Saavedra, J. Hinojosa, Y. Chandra, and R. Das, "Multi-scale modelling of rolling shear failure in crosslaminated timber structures by homogenisation and cohesive zone models," International Journal of Solids and Structures, vol. 81, pp. 219-232, 2016.

[20] D. Bobacz, Behavior of Wood in Case of Fire: Proposal for a Stochastic Dimensioning of Structural Elements, Müller, Marshfield, WI, USA, 2008.

[21] Z. H. Wang, L. Li, and Y. X. Zhang, "Bond-slip model considering freeze-thaw damage effect of concrete and its application," Engineering Structures, vol. 201, Article ID 109831, 2019. 
[22] Z. H. Wang, L. Li, Y. X. Zhang et al., "Reinforcement model considering slip effect," Engineering Structures, vol. 198, Article ID 109493, 2019.

[23] Y. Song, "Finite-element implementation of piezoelectric energy harvesting system from vibrations of railway bridge," Journal of Energy Engineering, vol. 145, Article ID 04018076, 2019.

[24] J. Wu, Q. S. Yan, S. P. Huang, C. Zou, J. T. Zhong, and W. F. Wang, "Finite element model updating in bridge structures using Kriging model and Latin hypercube sampling method," Advances in Civil Engineering, vol. 2018, Article ID 8980756, 11 pages, 2018.

[25] S. Nasrin and A. Ibrahim, "Finite-element modeling of UHPC hybrid bridge deck connections," International Journal of Advanced Structural Engineering, vol. 10, no. 3, pp. 199-210, 2018.

[26] H. Takeda and J. R. Mehaffey, "WALL2D: a model for predicting heat transfer through wood-stud walls exposed to fire," Fire and Materials, vol. 22, no. 4, pp. 133-140, 1998.

[27] J. M. Franssen, "SAFIR: a thermal/structural program for modeling structures under fire," Engineering Journal-American Institute of Steel Construction Inc, vol. 42, no. 3, pp. 143-158, 2005.

[28] A. Paolini, S. Kollmannsberger, C. Winter et al., "A high-order finite element model for vibration analysis of cross-laminated timber assemblies," Building Acoustics, vol. 24, no. 3, pp. 135-158, 2017.

[29] M. Betti, M. Brunetti, M. P. Lauriola, M. Nocetti, F. Ravalli, and B. Pizzo, "Comparison of newly proposed test methods to evaluate the bonding quality of Cross-Laminated Timber (CLT) panels by means of experimental data and finite element (FE) analysis," Construction and Building Materials, vol. 125, pp. 952-963, 2016.

[30] A. R. Díaz, E. I. Saavedra Flores, S. J. Yanez, D. A. Vasco, J. C. Pina, and C. F. Guzmán, "Multiscale modeling of the thermal conductivity of wood and its application to crosslaminated timber," International Journal of Thermal Sciences, vol. 144, pp. 79-92, 2019. 